\title{
Dimethyl fumarate increases fetal hemoglobin, provides heme detoxification, and corrects anemia in sickle cell disease
}

\author{
Sriram Krishnamoorthy, ${ }^{1}$ Betty Pace, ${ }^{2}$ Dipti Gupta, ${ }^{1}$ Sarah Sturtevant, ${ }^{1}$ Biaoru Li, ${ }^{2}$ Levi Makala, ${ }^{2}$ \\ Julia Brittain, ${ }^{3}$ Nancy Moore, ${ }^{1}$ Benjamin F. Vieira, ${ }^{1}$ Timothy Thullen, ${ }^{4}$ Ivan Stone, ${ }^{4}$ Huo Li, ${ }^{5}$ \\ William E. Hobbs, ${ }^{1}$ and David R. Light ${ }^{1}$ \\ ${ }^{1}$ Hematology Research, Bioverativ, Waltham, Massachusetts, USA. ${ }^{2}$ Department of Pediatrics, and ${ }^{3}$ Vascular Biology \\ Center, Augusta University, Augusta, Georgia, USA. ${ }^{4}$ Preclinical Safety and ${ }^{5}$ Computational Biology, Biogen, Cambridge, \\ Massachusetts, USA.
}

\begin{abstract}
Sickle cell disease (SCD) results from a point mutation in the $\beta$-globin gene forming hemoglobin $\mathbf{S}$ (HbS), which polymerizes in deoxygenated erythrocytes, triggering recurrent painful vaso-occlusive crises and chronic hemolytic anemia. Reactivation of fetal $\mathrm{Hb}(\mathrm{HbF})$ expression ameliorates these symptoms of SCD. Nuclear factor (erythroid derived-2)-like 2 (Nrf2) is a transcription factor that triggers cytoprotective and antioxidant pathways to limit oxidative damage and inflammation and increases $\mathrm{HbF}$ synthesis in $\mathrm{CD} 34^{+}$stem cell-derived erythroid progenitors. We investigated the ability of dimethyl fumarate (DMF), a small-molecule Nrf2 agonist, to activate $\gamma$-globin transcription and enhance $\mathrm{HbF}$ in tissue culture and in murine and primate models. DMF recruited $\mathrm{Nrf} 2$ to the $\gamma$-globin promoters and the locus control region of the $\boldsymbol{\beta}$-globin locus in erythroleukemia cells, elevated HbF in SCD donor-derived erythroid progenitors, and reduced hypoxia-induced sickling. Chronic DMF administration in SCD mice induced HbF and increased Nrf2-dependent genes to detoxify heme and limit inflammation. This improved hematological parameters, reduced plasma-free $\mathrm{Hb}$, and attenuated inflammatory markers. Chronic DMF administration to nonanemic primates increased $\gamma$-globin mRNA in BM and HbF protein in rbc. DMF represents a potential therapy for SCD to induce $\mathrm{HbF}$ and augment vasoprotection and heme detoxification.
\end{abstract}

Conflict of interest: SK, DG, SS, NM, BFV, WEH, and DRL are employees and stakeholders of Bioverativ Therapeutics. $\mathrm{TT}$, IS, and $\mathrm{HL}$ are employees and stakeholders of Biogen.

Submitted: July 20, 2017 Accepted: September 7, 2017 Published: October 19, 2017

\section{Reference information:} JCI Insight. 2017;2(20):e96409. https://doi.org/10.1172/jci. insight.96409.

\section{Introduction}

Sickle cell disease (SCD) is an inherited rbc disorder caused by a point mutation (Glu6 $\rightarrow$ Val) in the $\beta$-globin gene leading to expression of the $\beta^{\text {s}}$-globin subunit of hemoglobin $\mathrm{S}(\mathrm{HbS})$. HbS polymerizes in low-oxygen conditions, deforming rbc into sickle-shaped cells that trigger a complex pathophysiology such as recurrent, painful vaso-occlusive crises (VOC) and chronic hemolytic anemia (1). VOC in SCD results from multiple pathological mechanisms triggered by chronic hemolysis, vascular inflammation, cellular adhesion, and thromboinflammatory processes. This pathology is exacerbated by activation of the vascular endothelium by TNF- $\alpha$ and other inflammatory cytokines (2) and products of hemolysis, including free $\mathrm{Hb}$, heme, and iron. Free heme and hemin can activate vascular endothelium and leukocytes (3) and has been demonstrated to induce acute chest syndrome in SCD mouse models (4). Heme mediates these pathophysiological events by a mechanism shown to depend on the TLR4 signaling pathway in a mouse model of SCD $(4,5)$. Scavengers of free $\mathrm{Hb}$ including haptoglobin and hemopexin mediate a positive effect on vascular function in both a preclinical model of hemolytic injury in guinea pigs (6) and in a mouse model of SCD (7). In addition, sickle rbc are more adherent to the vascular endothelium than normal rbc (8), which may further contribute to VOC and hemolysis. Adhesive interactions lead to formation of heterocellular aggregates that obstruct blood flow to induce ischemic tissue damage, which leads to the prolonged exposure of rbc to deoxygenated conditions, promoting further $\mathrm{HbS}$ polymerization and hemolysis (9).

Fetal $\mathrm{Hb}(\mathrm{HbF})$ is the major $\mathrm{Hb}$ produced throughout fetal development; during the first year of life, $\gamma$-globin expression is replaced by adult $\beta$-globin expression: a process known as $\mathrm{Hb}$ switching. As $\mathrm{HbF}$ levels 
decrease and $\mathrm{HbS}$ increases, the symptoms of SCD begin to manifest clinically. HbF induction in adult SCD patients is beneficial in ameliorating clinical symptoms and complications (10). HbF is composed of $\gamma$-globin chains encoded by the duplicated $H B G 1$ ( ${ }^{\mathrm{A}} \gamma$-globin) and $H B G 2\left({ }^{\mathrm{G}} \gamma\right.$-globin) genes on chromosome 11 . The normal contribution of ${ }^{\mathrm{G}} \gamma$-globin or ${ }^{\mathrm{A}} \gamma$-globin to total $\mathrm{HbF}$ varies between individuals (11), with the average newborn ratio of 3:1 in favor of ${ }^{G} \gamma$-globin dropping to 2:3 in adults (12). Individuals with hereditary persistence of fetal $\mathrm{Hb}(\mathrm{HPFH})$ overexpress one or both of the $\gamma$-globin genes as adults. HPFH promoter mutants exhibit elevated expression of ${ }^{A} \gamma$-globin or ${ }^{G} \gamma$-globin (13-15). Inheritance of HPFH with the $\beta^{S}$-globin mutation results in a milder clinical course and fewer disease complications due to the high circulating levels of $\mathrm{HbF}(16)$. Also, sickle cell mouse models with elevated levels of $\mathrm{HbF}$ resulted in amelioration of intravascular sickling and a concomitant reduction in hemolysis, oxidative stress, and systemic inflammation (17).

Strategies to reactivate $\gamma$-globin expression have been used successfully in mouse models of SCD to ameliorate the disease phenotype (18). Increasing $\mathrm{HbF}$ is the major mechanism of action of hydroxyurea (HU), the first FDA-approved drug for treating SCD. HU treatment increases HbF-positive rbc (F-cells) and total $\mathrm{Hb}$, ameliorates the symptoms of SCD, and improves long-term survival $(10,19,20)$. Thus, there is ongoing research efforts to develop strategies of $\mathrm{HbF}$ induction by pharmacologic or genetic manipulation of transcription activators and repressors of the $\gamma$-globin genes. In addition to HU, several other experimental drugs are under investigation for inducing $\mathrm{HbF}$, such as pomalidomide, DNA methyl transferase inhibitors, HDAC inhibitors, and several others $(21,22)$.

Nuclear factor (erythroid derived-2)-like 2 (Nrf2) is a basic leucine zipper transcription factor well established for its role in cellular cytoprotective and antioxidant actions. Nrf2 is sequestered in the cytoplasm under steady-state conditions by Keap1, a Kelch-domain protein that targets Nrf2 for proteasomal degradation. Modification of Keap1 by oxidant stress or small-molecule inhibitors decreases the interaction of Keap1 and Nrf2, allowing nuclear translocation and activation of Nrf2 target genes that harbor the antioxidant response element (ARE) where Nrf2 binds and activates transcription (23). The proximal promoters of the HBG1 and HBG2 genes are conserved (24) and contain consensus ARE sites. Drug-mediated $\mathrm{Nrf} 2$ activation leads to induction of $\mathrm{HbF}$ at both transcript and protein levels in cultured $\mathrm{CD} 34^{+}$stem cell-derived erythroid cells (25).

In the present study, we investigated the role of dimethyl fumarate (DMF), a small-molecule Nrf2 agonist, as an activator of $\gamma$-globin transcription to enhance levels of $\mathrm{HbF}$ in SCD donor-derived erythroid progenitor cells, SCD transgenic mice, and nonanemic cynomolgus monkeys. DMF is currently marketed as Tecfidera, an orally active, gastroresistant pharmaceutical formulation of DMF, approved for the treatment of multiple sclerosis (26). In vivo DMF is readily converted to the bioactive metabolite monomethyl fumarate (MMF). The Townes SCD mice used in the study express one of the two human $\gamma$-globin genes that contribute to the production of human $\mathrm{HbF}$ (27). We used these SCD mice to study the ability of $\mathrm{DMF}$ to induce $\mathrm{HbF}$ and to induce cytoprotective genes, which are able to limit vascular inflammation and directly protect against the circulating toxic products of rbc hemolysis (5). Reduction of Keap1 activity in SCD mice by genetic mutation results in Nrf2 activation, decreased inflammation, and tissue damage and demonstrates that cytoprotection by Nrf2 is beneficial in SCD (28). In the present study, we further investigated the expression of cytoprotective proteins controlled by Nrf2, including heme oxygenase-1 (HO-1), ferritin, haptoglobin, and hemopexin, all of which are directly relevant to mitigation of the toxic effects of intravascular hemolysis observed in SCD by metabolizing free $\mathrm{Hb}$, hemin, and iron.

\section{Results}

$D M F$ and $M M F$ induce HbF in erythroid progenitors generated from SCD blood peripheral blood mononuclear cells $(P B M C)$. Previously in studies by our group, $\mathrm{DMF}$ and its bioactive metabolite MMF were shown to increase $\mathrm{HbF}$ in erythroid progenitors derived from non-SCD subjects generated from normal BM CD $34^{+}$stem cells similarly to treatment with $\mathrm{HU}$ (29). In the present study, PBMC from adult and pediatric SCD subjects were tested for $\mathrm{HbF}$ induction in the presence of varying concentrations of MMF, DMF with or without HU. Significant increases in the level of $\gamma$-globin mRNA, the ratio of $\gamma / \beta$-globin mRNA, and the percentage of F-cells were observed with all treatments (Figure $1, A-C$ ). The greatest average increase in $\gamma / \beta$-globin mRNA was observed for SCD erythroid progenitors treated with a combination of DMF and HU, suggesting that treatment with HU does not interfere with the ability of DMF to induce HbF. Treatment with DMF $(30 \mu \mathrm{M})$ resulted in a 2.9- \pm 0.30-fold increase, treatment with MMF $(30 \mu \mathrm{M})$ resulted in a $4.8- \pm 3.3$-fold increase, and treatment with $\mathrm{HU}(10 \mu \mathrm{M})$ resulted in a 7.9- \pm 3.2-fold increase in $\gamma$-globin mRNA above controls (Figure 1A). 
A

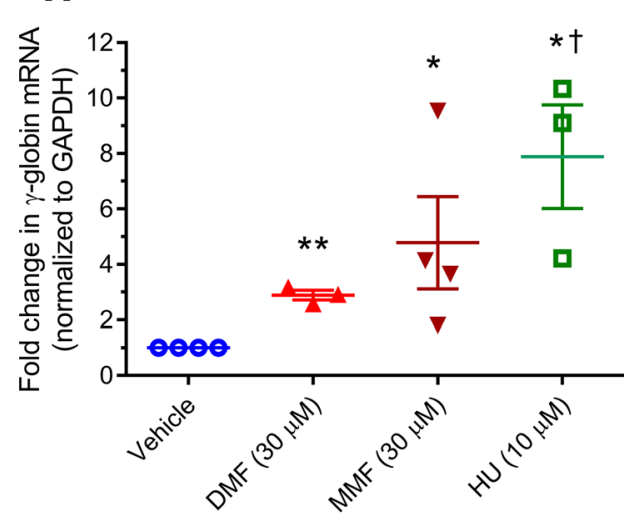

B

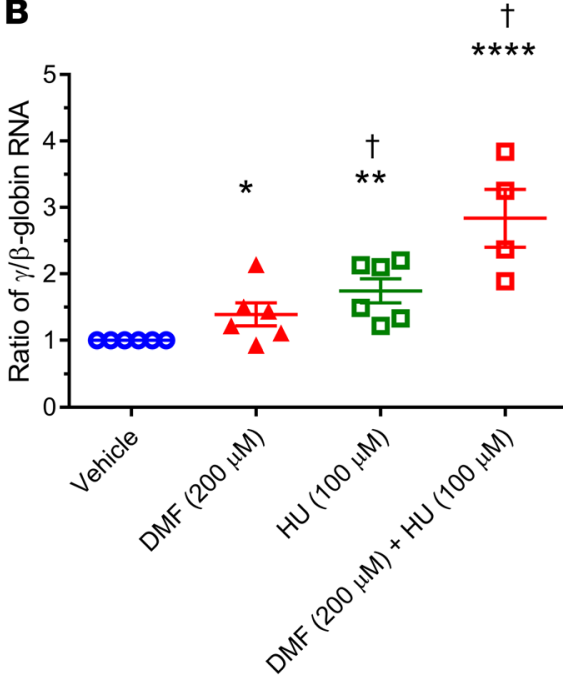

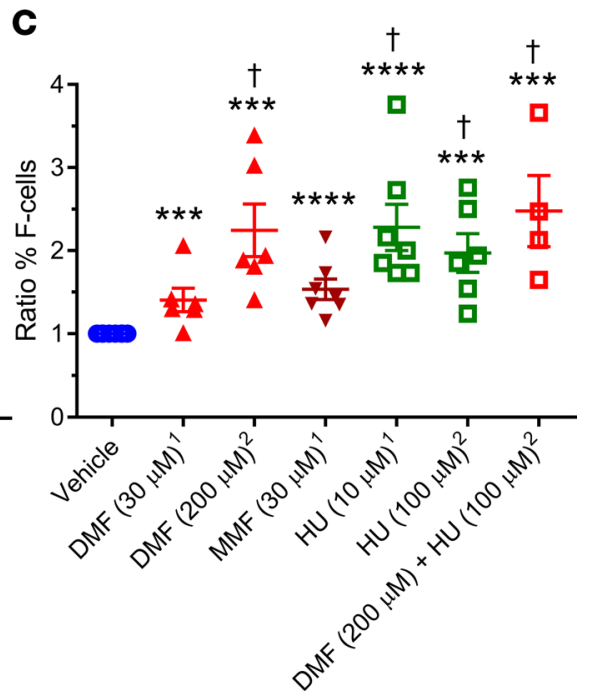

Figure 1. DMF and MMF induce $\gamma$-globin mRNA and increase HbF-positive cells (F-cells) in erythroid progenitor cells derived from SCD donor blood PBMC. Erythroid progenitor cells were cultured and differentiated from the peripheral blood mononuclear (PBMC) fraction of sickle cell disease (SCD) donor blood (see Supplemental Table 1) and exposed to test compounds as described in Methods with untreated cells used as controls. (A) Levels of $\gamma$-globin and GAPDH mRNA were determined between day 13 and 15 by ddPCR analysis and normalized to DMSO-treated control cells $(n=3-4$ donors) (B) Levels of $\gamma$-globin, $\beta$-globin, and GAPDH mRNA were determined on day 11 by real-time PCR analysis, and the ratio of $\gamma / \beta$-globin mRNA was normalized to control cells ( $n=4-6$ donors). (C) F-cells were quantified by flow cytometry between day 11 and 15 , and the $\%$ F-cells was normalized to untreated cells ( $n=4-7$ donors). Results are presented as mean \pm SEM. All $P$ values calculated with student $t$ test, 2 -tailed $\left({ }^{*} P<0.05,{ }^{* *} P<0.01,{ }^{* * *} P<0.005,{ }^{* * * *} P<0.001\right)$. One-way ANOVA testing showed significant differences among means $(P<0.05$ for all 3 panels). In addition, $P$ values determined by Bonferroni's multiple comparison test is also indicated ( $\dagger$ refers to adjusted $P<0.05$ when compared with vehicle group). ${ }^{1} \mathrm{SCD}$ donors from Biogen site, ${ }^{2} \mathrm{SCD}$ donors from Augusta University site.

Using UPLC, significant increases in both the ${ }^{\mathrm{G}} \gamma$-globin and ${ }^{\mathrm{A}} \gamma$-globin chains were observed (Figure $2 \mathrm{~A}$ ), indicating that DMF is capable of increasing expression of both the $H B G 1$ and the $H B G 2$ genes. In addition, significant increases in $\mathrm{HbF}$ as a percentage of total $\mathrm{Hb}$ were calculated from the total increase in the individual $\gamma$-globin chains as 1.83- \pm 0.40-fold for DMF, 2.06- \pm 0.48 -fold for MMF, and 2.8- \pm 1.12 -fold for HU compared with DMSO control (Figure 2B).

Inhibition of sickling in DMF-treated SCD erythroid cells. Erythroid cells differentiated from SCD PBMC in the presence of DMF or MMF $(30 \mu \mathrm{M})$ or DMSO control were incubated under hypoxic conditions to induce the phenotypic shape change of cell sickling for the same 3 donors used for the analysis shown in Figure 1A.

A

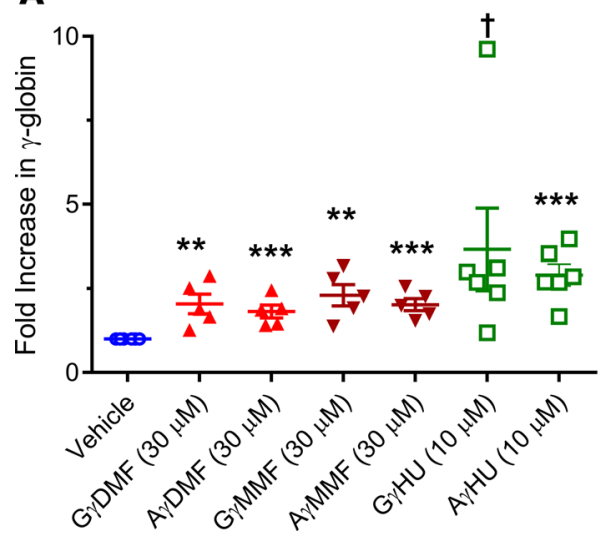

B

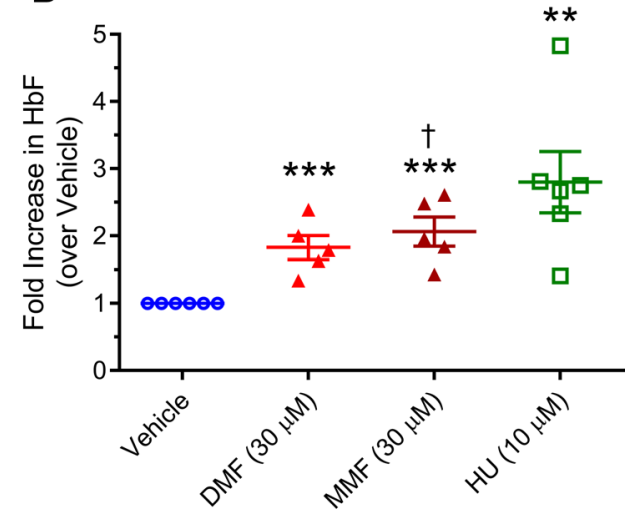

Figure 2. Analysis of ${ }^{\mathrm{A}} \gamma$-globin and ${ }^{\mathrm{C}} \gamma$-globin chains and hemoglobin levels by UPLC in SCD donor-derived erythroid cells. Variant analysis of $\gamma$-globin protein chains expressed in erythroid cells differentiated from the PBMC fraction of SCD donor blood was carried out using reverse-phase UPLC column chromatography. (A) Fold changes in individual $\gamma$-globin peptide chains for each donor calculated over vehicle control $(n=5-6$ donors). (B) Total HbF percentages were calculated from the individual $\gamma$-globin variant chains $(n=5-6$ donors). Results are presented as mean \pm SEM. All $P$ values calculated with student $t$ test, 2 -tailed $\left({ }^{* *} P<0.01,{ }^{* * *} P<0.001\right)$. One-way ANOVA testing showed significant differences among means $(P<0.05$ for both the panels). In addition, $P$ values determined by Bonferroni's multiple comparison test is also indicated ( $\dagger$ refers to adjusted $P<0.05$ when compared with vehicle group). 

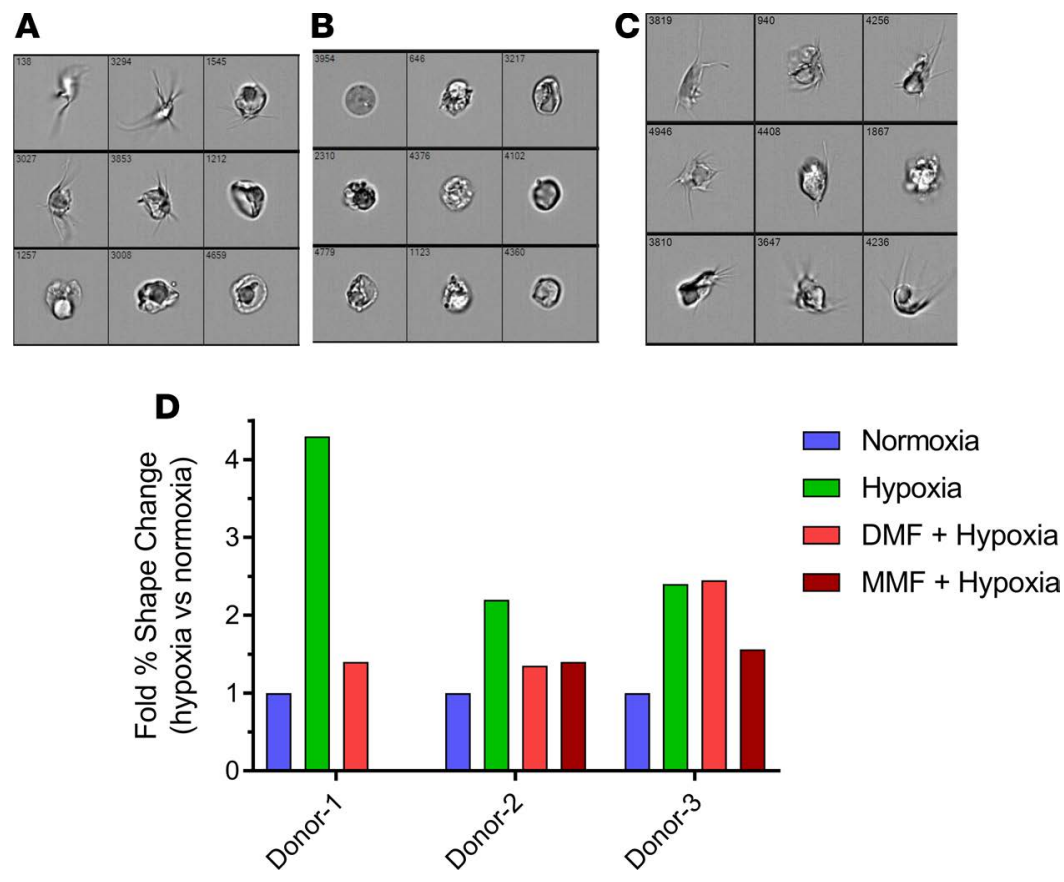

Figure 3. DMF/MMF-treated erythroid cells derived from SCD donors resist sickling triggered by hypoxia. Erythroid progenitor cells were isolated from the PBMC fraction of SCD donor blood and differentiated toward erythroid cells in the presence of $30 \mu \mathrm{M}$ DMF, $30 \mu \mathrm{M}$ MMF, or DMSO control and then challenged with hypoxia treatment to induce sickling. Cell images were acquired and sorted using Amnis ImageStream X Mark II, and shape change was quantitated using IDEAS software (Amnis Imagestream) following an algorithm adapted from van Beers et al. (49). (A) Representative images of the cell population under hypoxia, (B) cells gated as normal, and (C) cells gated as abnormal or sickled (all magnifications 60x). (D) Quantitation of sickling under normoxia and hypoxia with and without DMF or MMF treatment for 3 SCD subjects.

Representative images of the mixture of cells under hypoxia (Figure 3A), the normal cell gate (Figure 3B), and the abnormal sickle cell gate (Figure 3C) are shown. DMSO control samples under hypoxic and normoxic treatments were used as vehicle controls. Under normoxia, the percentage of abnormally shaped cells were $7.3 \% \pm 1.2 \%$, which was elevated to $22 \% \pm 9.6 \%$ under hypoxia. DMF-treated samples under hypoxia showed a decreased level of abnormal cells of $13 \% \pm 4.1 \%$ for all 3 donors, which amounts to a $>$ $80 \%$ reduction in sickling (Figure 3D). Incubations with MMF also demonstrated reduction in sickling in the 2 donors in whom it was tested.

$D M F$ increases Nrf2 occupancy of the $\gamma$-globin promoter. To understand mechanisms of the HbF induction by DMF that was observed in SCD erythroid progenitor cells, ChIP assay was performed using KU812 erythroleukemia cells. DMF increased Nrf2 occupancy of the $\gamma$-globin promoter ARE about 15 -fold compared with chromatin enrichment with untreated cells or IgG control (Figure 4A), while the high occupancy of the TATA-binding site by transcription factor II D (TFIID) observed at steady state was not changed by DMF treatment (Figure 4A). As further controls, occupancy by Nrf2 or TFIID at the ${ }^{\mathrm{G}} \boldsymbol{\gamma}$-globin transcription initiation site (G-CRE) located at $-1,222$ bp from the ${ }^{\mathrm{G}} \gamma$-globin gene transcription initiation site was not increased in DMF-treated KU812 cells (Figure 4B). Finally, the potential for DMF to increase Nrf2 binding to HS2 and HS3 in the $\beta$-globin locus control region (LCR) was tested. We observed an approximately 13-fold increase of Nrf2 binding to HS2 (Figure 4C) with no significant increase in Nrf2 interaction at HS3 (Figure 4D).

$D M F$ i.p. treatment produces therapeutic MMF plasma levels in SCD mice. In the clinic, DMF is rapidly converted to MMF, which is its major bioactive metabolite (30). In a nonclinical study, DMF delivered to the small intestine of anesthetized rats resulted in the peak plasma levels of MMF within 9-15 minutes (31). In order to confirm plasma levels of MMF in SCD mice, DMF (50 mg/kg in $0.08 \%$ hydroxypropyl methylcellulose [HPMC]) was dosed by i.p. injection acutely to the Townes SCD mice (Hb SS) and heterozygous $\mathrm{Hb}$ AS and homozygous $\mathrm{Hb}$ AA littermate control, and to normal C57/BL/6 mice. Plasma levels of MMF were determined (Supplemental Methods; supplemental material available online with this article; https:// doi.org/10.1172/jci.insight.96409DS1). As shown in Supplemental Table 2, the plasma concentrations of MMF in the Townes HbSS mice were $12.3 \pm 2.9 \mu \mathrm{g} / \mathrm{ml}(95 \pm 23 \mu \mathrm{M})$; plasma levels were similar in all 4 mouse strains, ranging from $5.6-22 \mu \mathrm{g} / \mathrm{ml}(43$ to $172 \mu \mathrm{M})$, pertinent to the $30-\mu \mathrm{M}$ concentration used in the in vitro studies with $\mathrm{CD} 34$ cells.

$D M F$ upregulates $H b F$ and antioxidant genes in SCD mice. First, acute induction of $\mathrm{HbF}$ and other genes beneficial for SCD was tested in vivo following administration of a single $100 \mathrm{mg} / \mathrm{kg}$ dose of DMF to Townes SCD mice by oral gavage (32). Expression of ${ }^{\mathrm{A}} \gamma$-globin and other Nrf2-dependent genes was monitored at 
A
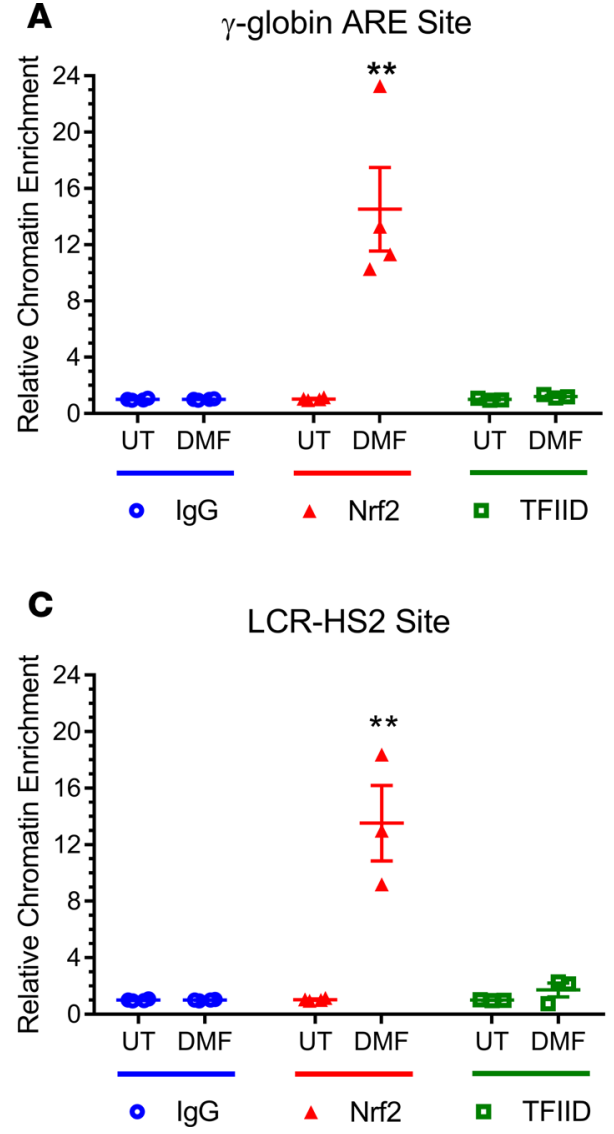

B

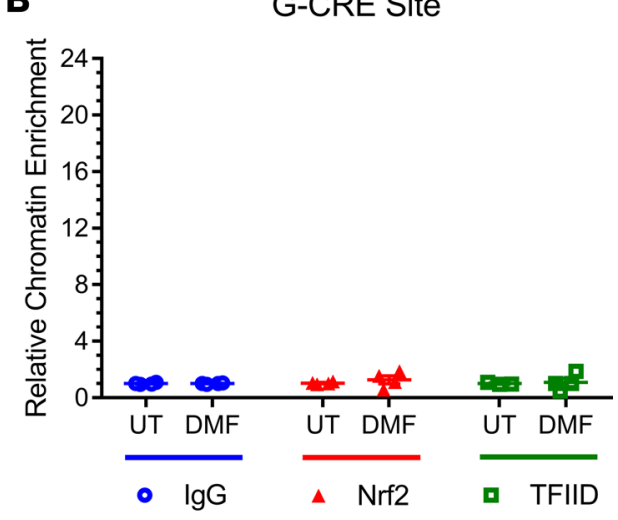

D

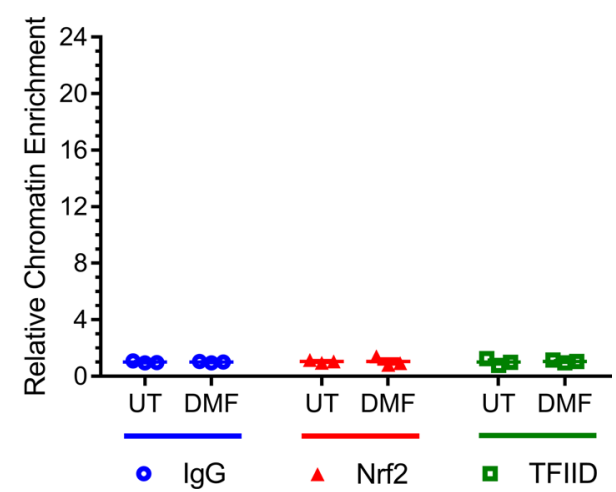

Figure 4. DMF increases Nrf2 occupancy at both the ARE of $\gamma$-globin and the LCR-HS2 sites. ChIP assays were performed with KU812 cells treated for 48 hours with $200 \mu \mathrm{M}$ DMF in Iscove modified Dulbecco buffer (IMDM) compared with IMDM-treated control cells (UT). Enrichment of chromatin DNA precipitated from isolated KU812 erythroleukemia cell nuclei was detected by qPCR following precipitation with a specific anti-Nrf2 antibody (Nrf2), a nonspecific control antibody (IgC), or an antibody to the ubiquitous TATA-binding transcription factor TFIID. (A) Occupancy of the $\gamma$-globin promoters ARE by Nrf2 and TFIID in untreated and DMF-treated cells $(n=3-4)$. (B) Nrf2 and TFIID occupancy of a negative control region (G-CRE) located at $-1,222$ bp in ${ }^{C} \gamma$-globin promoter following either Nrf2 or TFIID precipitation $(n=3-4)$. Nrf2 and TFIID occupancy of the locus control region (LCR) DNase hypersensitivity sites (HS) for (C) LCR-HS2 and (D) LCR-HS3 ( $n=3-4$ for both the panels) were also analyzed ( $n=3-4$ for both panels). Enrichment of DNA in untreated nonspecific control IgC precipitated samples was used as control, and qPCR data were analyzed using the $\Delta \Delta C \mathrm{C}$ method to calculate the fold chromatin enrichment for each site. Results in each panel are reported as mean \pm SEM. All $P$ values calculated with student $t$ test, 2 -tailed $\left({ }^{* *} P<0.01\right)$.

specific time points after injection compared with untreated animals at time zero. Gene expression analysis by quantitative PCR (qPCR) displayed differential regulation of several Nrf2-responsive genes in a temporal and tissue-specific manner (Figure 5). Of interest, DMF treatment elevated ${ }^{\mathrm{A}} \gamma$-globin mRNA levels in the spleen of SCD mice at 3, 6, and 24 hours after administration (Figure 5A). In addition, DMF upregulated the expression of Nrf2-responsive genes in spleen tissue, including Nqo1 (Figure 5B) and, importantly, increased cytoprotective and heme detoxification genes such as HO-1 and hemopexin in the spleen, liver, and whole blood (Figure 5, C-F). Regulation of genes in these target tissues followed a temporal pattern. For example, NQO1 and HO-1 in spleen showed a marked upregulation at 3 hours, but were downregulated below baseline at subsequent time points (Figure 5, B and C). In liver and whole blood, maximal increases for some responsive genes such as hemopexin and HO-1 were observed at 6 hours after DMF administration (Figure 5, D-F), and the pattern of gene expression varied for different genes in this study.

Next, a chronic DMF dosing study was performed in Townes SCD mice by daily oral gavage to test whether DMF treatment can lead to sustained elevations in $\mathrm{HbF}$ in rbc. During chronic treatments, mice were administered DMF at $100 \mathrm{mg} / \mathrm{kg}$ or vehicle ( $0.8 \% \mathrm{HPMC}, 15 \mathrm{ml} / \mathrm{kg}$, per os [PO]) once daily by oral gavage 6 days a week for 7 weeks. Blood samples were collected and ${ }^{\mathrm{A}}$-globin protein levels in whole blood obtained from DMF- and vehicle-treated mice at weeks 4 and 7 were determined by Western blotting. DMF-treated mice showed an increase in $\mathrm{HbF}$ protein levels of 1.47 -fold at week $4(P=0.0002)$ and an increase of 2.22 -fold at week $7(P=0.0021)$ compared with vehicle-treated controls (Figure 6, A and B). 
A

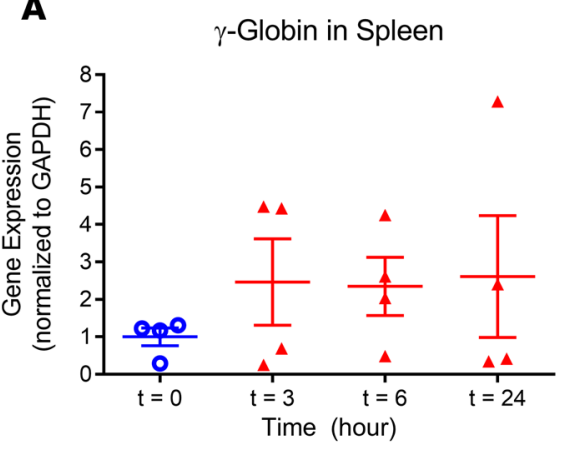

D

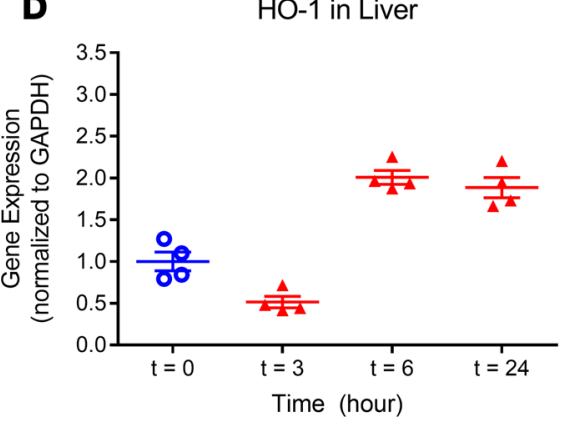

B

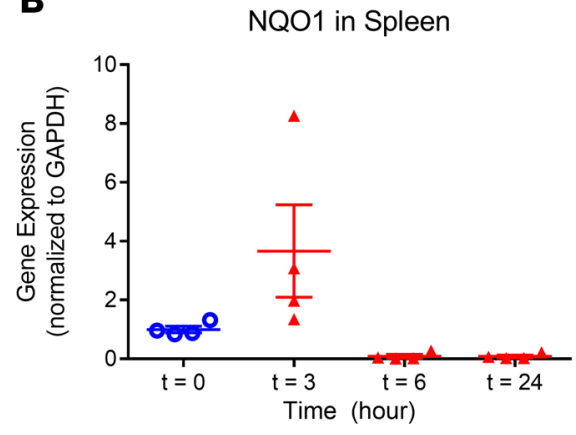

E

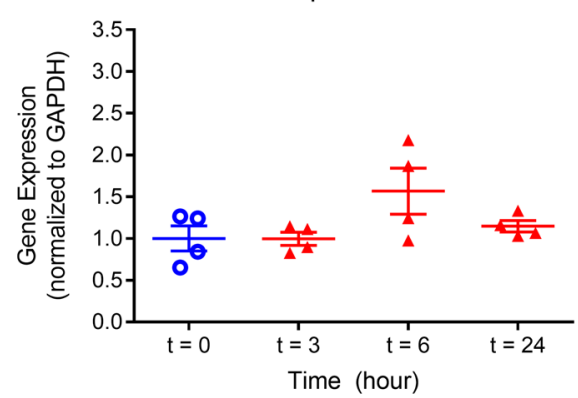

C

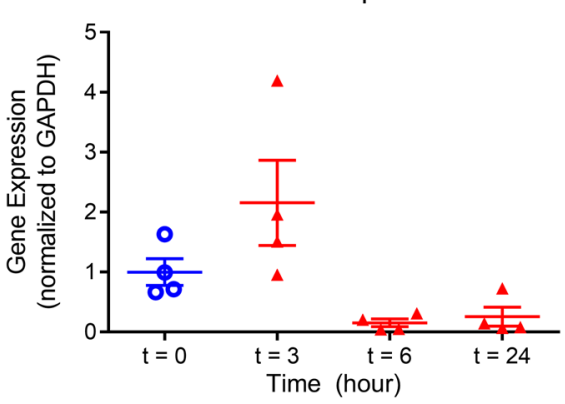

$\mathbf{F}$

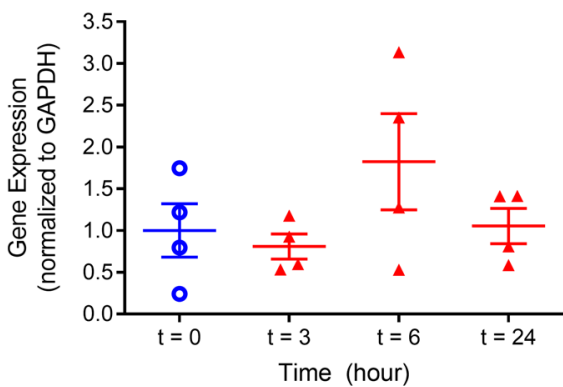

Figure 5. DMF acutely upregulates $\mathrm{A} \gamma$-globin and other Nrf2-dependent genes in SCD mice. Townes SCD SS mouse (8-12 weeks old) were randomized into 4 groups of 4 each, administered a single dose of $100 \mathrm{mg} / \mathrm{kg}$ DMF in $0.8 \%$ HPMC by oral gavage, and euthanized at 3, 6, or 24 hours. Untreated mice at time zero were the controls. After euthanasia, whole blood, liver, and spleen were harvested and mRNA extracted and profiled by real-time PCR. Splenic expression of genes of interest in sickle cell disease including (A) ${ }^{A} \gamma$-globin and (C) heme oxygenase 1 (HO-1) compared with (B) the Nrf2 responsive gene $\mathrm{NAD}(\mathrm{P}) \mathrm{H}$ dehydrogenase quinone 1 (NQO1). Also tested were hepatic expression of (D) HO-1 and (E) hemopexin and (F) expression of HO-1 in whole blood cells. The average expression normalized to $\mathrm{GAPDH}$ at time zero was calculated and used to calculate the relative fold change in gene expression in all mice and time points. Results are represented as mean $\pm \mathrm{SEM}, n=4$ for all the groups. The changes observed in the levels of the mRNA of the indicated genes were not statistically significant compared with baseline $(t=0)$.

Chronic administration of DMF improves anemia and induces $\gamma$-globin mRNA in spleen. To study the ability of sustained DMF treatment to improve hematological parameters in Townes SCD mice, $50 \mathrm{mg} / \mathrm{kg} \mathrm{DMF}$ or vehicle (0.08\% HPMC, $15 \mathrm{ml} / \mathrm{kg}$ ) was administered twice daily by i.p. injection for 6 weeks. After 6 weeks, whole blood samples collected from the mice were subjected to complete blood count (CBC) analysis, and significant changes in several parameters indicated improvements in anemia (Figure 7 and Supplemental Table 3). Notably, DMF-treated mice showed higher Hb levels (Figure 7A), higher rbc count (Figure 7B), increased mean corpuscular $\mathrm{Hb}$ (MCHC, Figure 7C), lowered red cell distribution width (RDW, Figure 7D), and lowered $\mathrm{Hb}$ distribution width (HDW, Figure 7E) compared with vehicle-treated mice. Hb levels in DMF-treated mice were significantly increased by $1.4 \mathrm{~g} / \mathrm{dl}$ compared with vehicle-treatedmice, and the rbc count showed a significant elevation of $1.4 \times 10^{6} / \mu 1(P<0.05)$. RDW, a measure of anisocytosis, and HDW, a measure that correlates with the number of dense or irreversible sickle cells (33), showed significant reduction in DMF-treated mice compared with vehicle-treated ones $(P<0.05)$. Furthermore, RDW and HDW showed good correlation, with DMF-treated animals showing both lower RDW and HDW (Figure 7F). Additional hematological parameters such as hematocrit, total leukocyte count, and MCV showed a trend toward improvement but were not statistically significant (Supplemental Table 3). RNA-sequencing (RNA-seq) analysis of spleen from Townes mice treated with DMF showed induction in the levels of $\gamma$-globin mRNA (Supplemental Figure 2). Together, the results from CBC analysis illustrate improvement in anemia in SCD mice treated with DMF.

Antiinflammatory and heme detoxification mechanisms activated by DMF. Haptoglobin is one of the downstream target genes of Nrf2 that is critical in sequestering plasma-free $\mathrm{Hb}$. Hepatic haptoglobin levels were significantly improved ( $>2$-fold, $P=0.023$ ) in SCD mice chronically dosed with DMF compared with vehicle (Figure $8 \mathrm{~A}$ ). Concurrent with these findings, plasma-free $\mathrm{Hb}$ levels were reduced significantly $(P=0.018)$ in DMF-treated mice compared with vehicle controls and approached levels in non-SCD 

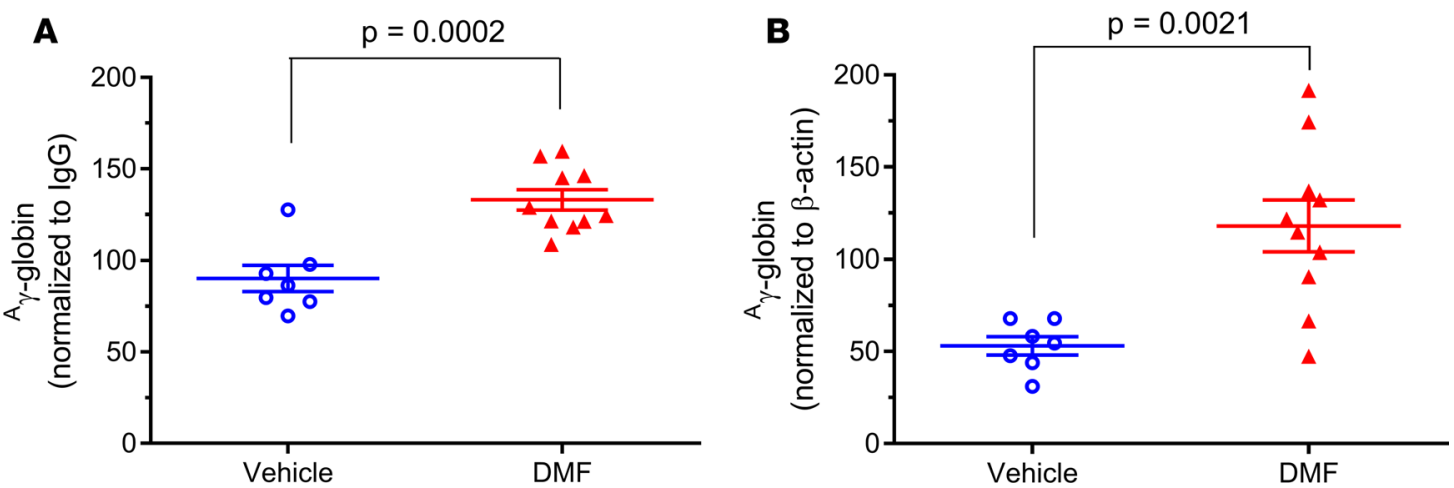

Figure 6. Chronic DMF administration increases fetal hemoglobin in SCD mice. The ability of DMF to increase expression of HbF protein by induction of the single human ${ }^{A} \gamma$-globin gene in Townes SCD SS mice was tested following chronic PO dosing. SCD mice were administered $100 \mathrm{mg} / \mathrm{kg}$ DMF or vehicle (per os [PO],quaque die [QD]) for 7 weeks. Following either 4 or 7 weeks of PO dosing, blood samples were collected and hemolysates prepared for testing for HbF levels by Western blotting. (A) Immunoblots costained and quantified for $\gamma$-globin and normalized to IgG at 4 weeks $(n=7-10)$ and (B) immunoblots for $\gamma$-globin normalized to $\beta$-actin at 7 weeks $(n=7-10)$. Results shown here are mean $\pm \mathrm{SEM}$, and $P$ values were calculated with student $t$ test, 2-tailed.

mice (Figure 8B). Thus, DMF is able to improve heme detoxification by haptoglobin, which primarily acts on plasma-free $\mathrm{Hb}$ arising from hemolysis, in agreement with a recent study (34). Since haptoglobin is an acute phase protein, we wanted to investigate if DMF treatment affected the levels of other acute phase proteins or molecules that signify hepatic inflammation or injury. It was indeed identified that haptoglobin elevation was a specific Nrf2-dependent response, since chronic DMF administration did not change the levels of other acute phase proteins in liver such as C-reactive protein (CRP), serum amyloid A, ceruloplasmin, and ALT (Supplemental Figure 1).

DMF treatment significantly $(P<0.05)$ lowered by $>50 \%$ plasma levels of IL-6 (Figure 9A) and hepatic levels of both TNF- $\alpha$ (Figure 9B) and keratinocyte chemoattractant (KC, murine ortholog of IL-8; Figure $9 \mathrm{C}$ ). The plasma levels of $\mathrm{KC}$ were also reduced, although the values were not statistically significant (data not shown). Finally, there was a significant reduction in the levels of vascular cell adhesion molecule 1 (VCAM-1) in liver homogenates from DMF-treated mice compared with vehicle-treated mice (Figure 9D).

Chronic DMF administration elevates $\gamma$-globin mRNA levels in the BM and HbF levels in rbc of cynomolgus monkeys. Cynomolgus monkeys were orally dosed with $25 \mathrm{mg} / \mathrm{kg}$ DMF quaque die (QD) for 90 days, using a dose derived from a previous toxicology study at Biogen, and following euthanasia at the end of the treatment period, BM levels of $\gamma$-globin mRNA were assessed using real-time PCR. Three hours after the last dose of DMF administration, DMF induced a significant 6-fold upregulation of $\gamma$-globin mRNA. At 6 hours after the last dose of DMF, $\gamma$-globin mRNA levels were still significantly elevated 1.5-fold (Figures 10, A and B). Blood samples collected on day 91 of the study demonstrated that $\mathrm{HbF}$ protein levels were upregulated by 1.4 -fold $(P<0.05)$ in the DMF treatment group compared with the vehicle (Figure 10C).

\section{Discussion}

The present report provides evidence that DMF could have beneficial actions in SCD at multiple levels to produce an additive effect toward ameliorating clinical symptoms and disease complications. DMF is a small molecule of which the primary mechanism of action is to increase the accumulation of Nrf2, a transcription factor that is involved in activation of downstream genes that are vital in protecting cells from injurious oxidative free radicals. Recently published reports have demonstrated the importance of the Nrf2 pathway in activating $\mathrm{HbF}$ in human erythroid cells differentiated from BM-derived $\mathrm{CD} 34^{+}$ progenitor cells (25). In this study, we observed $\mathrm{HbF}$ induction by DMF in SCD donor PBMC-derived erythroid progenitors. Furthermore, DMF reduced hypoxia-induced sickling in SCD erythroid progenitors and activated and recruited Nrf2 to the ARE site in the $\gamma$-globin promoters. In the Townes mouse model of SCD, DMF enhanced ${ }^{\mathrm{A}} \gamma$-globin expression and other Nrf2-dependent genes with beneficial effects in SCD, including increased heme detoxification. Chronic dosing of DMF in Townes SCD mice leads to elevation of $\mathrm{HbF}$, improvement in hematological parameters, reduction in plasma-free $\mathrm{Hb}$, and attenuation of inflammatory cytokines and markers. More importantly, chronic dosing of nonhuman primates with DMF led to significant induction of $\gamma$-globin transcript levels in the BM and in increased 
A

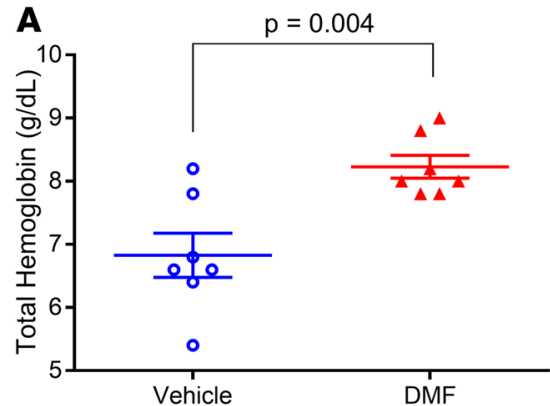

D

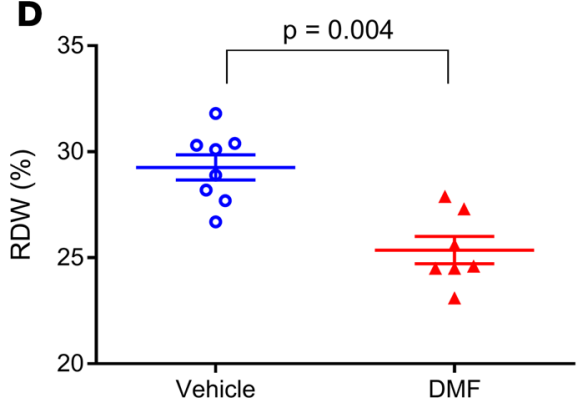

B

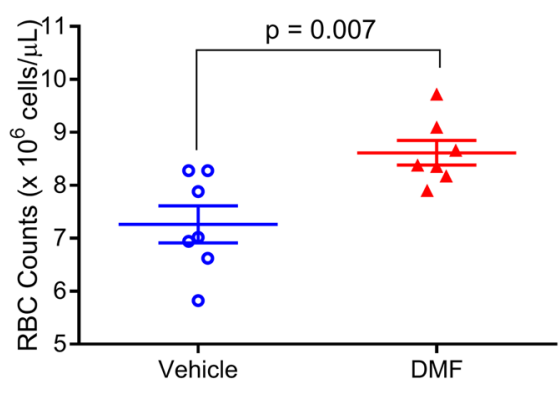

E

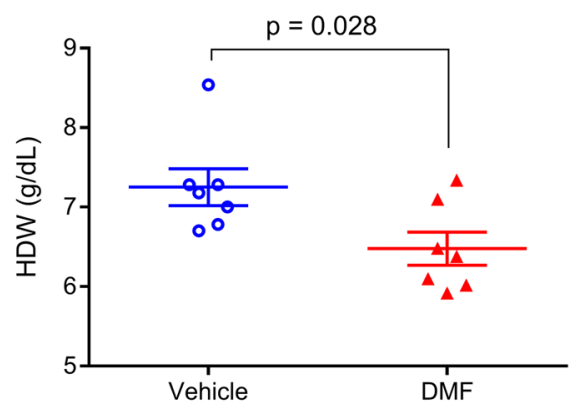

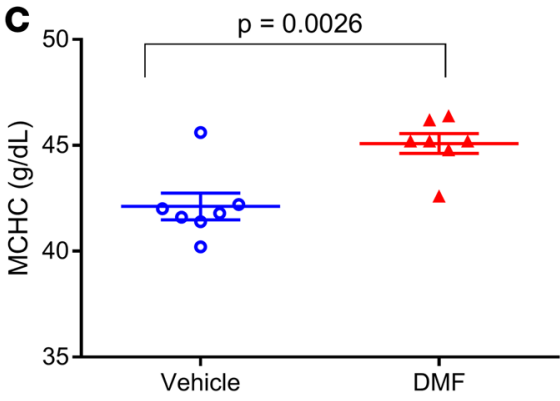

$\mathbf{F}$

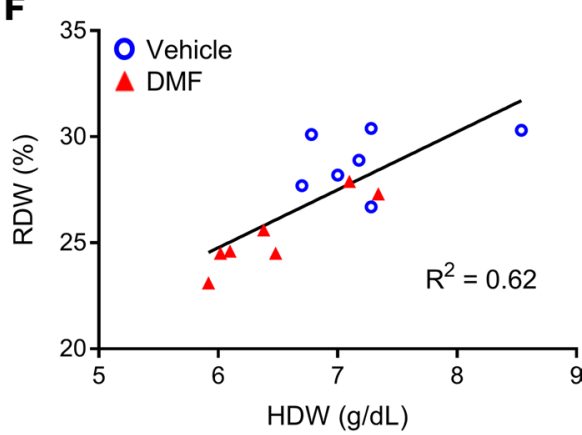

Figure 7. Chronic DMF treatment increases total hemoglobin and improves rbc parameters in SCD mice. Whole blood samples were collected from Townes SCD SS mice following 6 weeks administration of 50 mg/kg DMF or vehicle (i.p., twice a day [BID]) and subjected to CBC analysis. Hematological parameters indicating improvement of anemia included (A) total hemoglobin levels, (B) total rbc counts, (C) mean corpuscular hemoglobin concentration (MCHC), (D) red cell distribution width (RDW), and (E) hemoglobin distribution width (HDW). (F) A significant $\mathrm{R}^{2}$ correlation of 0.62 was observed between RDW and HDW. Results are represented as mean \pm SEM, $n=7$ for both vehicle and DMF groups. All $P$ values calculated with student $t$ test, 2-tailed.

$\mathrm{HbF}$ protein in circulating rbc. Thus, DMF represents a potential therapy for SCD that could induce $\mathrm{HbF}$ as well as augment vasculoprotective and heme detoxification mechanisms.

Based on clinical experience with $\mathrm{HU}, \mathrm{HbF}$ induction will prevent rbc sickling and hemolysis and decrease the downstream consequences of SCD, including VOC and vascular inflammation (10). Increasing $\mathrm{HbF}$ in SCD is considered to be safe and effective, as supported by data from individuals with sickle cell with hereditary persistence of fetal hemoglobin ( $\mathrm{SPFH}$ ) who produce high $\mathrm{HbF}$ levels $(16,35)$. The current study was a preclinical evaluation of the potential of $\mathrm{DMF}$ as a treatment option to induce $\mathrm{HbF}$ and increase F-cells in order to reduce rbc sickling that leads to hemolysis and VOC in SCD. HbF induction was studied in human erythroid progenitors generated from PBMC isolated from SCD donors (pediatric and adult). Erythroid progenitors treated with DMF or MMF, the bioactive metabolite of DMF, upregulated $\gamma$-globin mRNA and increased the percentage of F-cells. Combined treatment with DMF and HU produced an additive effect on $\gamma$-globin transcription in erythroid progenitor cells and $\mathrm{HbF}$ synthesis, suggesting that the combined treatment with $\mathrm{HU}$ will not interfere with the ability of DMF to induce $\mathrm{HbF}$.

In a mechanistic study of $\gamma$-globin activation by DMF, ChIP assays were used to measure occupancy by Nrf2 of selected sites in the $\beta$-globin locus in cultured human KU812 erythroleukemia cells. KU812 cells are a human leukemia cell line expressing both fetal $\gamma$-globin and adult $\beta$-globin genes shown to increase expression of $\mathrm{HbF}$ in response to known $\beta-\mathrm{Hb}$ switching agents, including heme and sodium butyrate (36). Our studies confirmed that Nrf2 activation leads to occupancy of the ARE consensus sites in the $\gamma$-globin gene promoters, in agreement with published data with K562 erythroleukemia cells and erythroid progenitors generated from normal peripheral CD34 ${ }^{+}$cells treated with the Nrf2 activator tert-butylhydroquinone (tBHQ) (25).

$\mathrm{HbF}$ induction, heme detoxification, and vascular protection were studied in vivo using Townes SCD mice. A single-dose pharmacodynamics study was carried out to evaluate the gene expression patterns of Nrf2-dependent genes in SCD mouse tissues. A single oral gavage administration of DMF induced expression of the ${ }^{\mathrm{A}} \gamma$-globin gene in the spleens of SCD mice. The enlarged spleen is an important hematopoietic organ in mice during anemic states and is the major site of extramedullary erythropoiesis in Townes SCD 

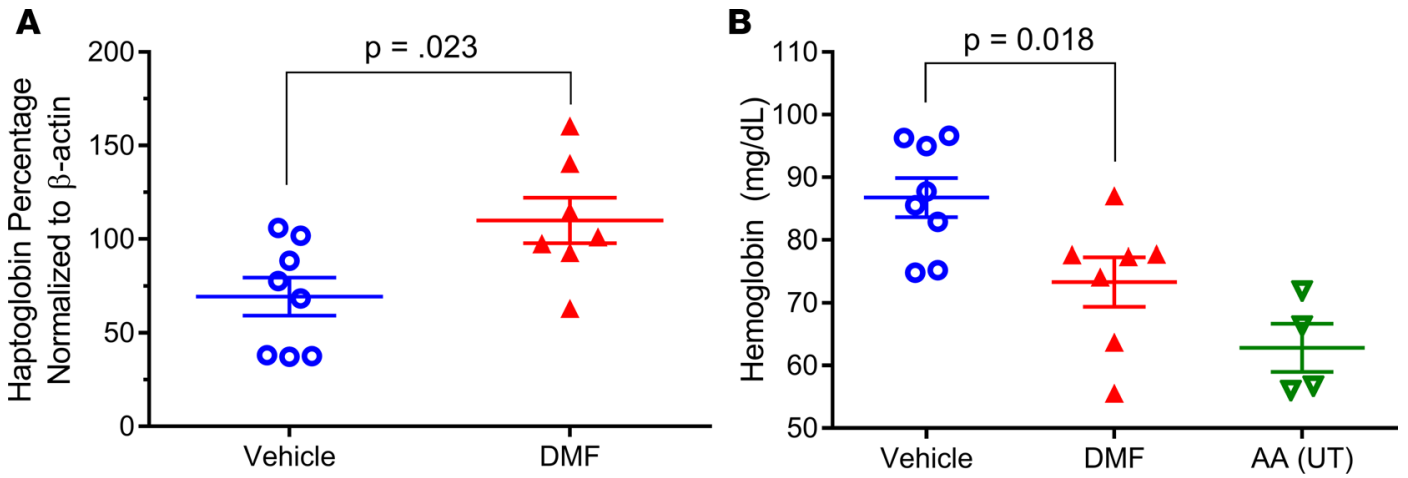

Figure 8. Chronic DMF treatment increases liver haptoglobin and decreases cell-free hemoglobin in blood of SCD mice. Townes SCD SS mice were administered with $50 \mathrm{mg} / \mathrm{kg}$ DMF (IP, BID) or vehicle for 6 weeks. (A) Liver samples harvested after euthanasia were homogenized for protein isolation, and samples were run on Western blots and stained for both haptoglobin and $\beta$-actin simultaneously. Band intensities were determined using a chemiluminescence imaging system and haptoglobin values normalized to $\beta$-actin $(n=7-8)$. (B) Plasma samples isolated from whole blood were tested for the cell-free fraction of hemoglobin levels using a colorimetric hemoglobin assay $(n=7-8)$. Plasma-free hemoglobin levels from nonsickler Townes SCD AA littermates $(n=4)$ are shown for comparison. All $P$ values calculated with student $t$ test, 2 -tailed.

mice. In addition, several Nrf2 target genes - including ones that aid in detoxifying products of hemolysis, namely HO-1, hemopexin, and ferritin heavy chain - were upregulated acutely. These results extend proof of target engagement and activation of the Nrf2 pathway by DMF in SCD mice. These results suggest that, upon the administration of a single DMF dose, Nrf2-mediated downstream gene regulation occurs in a tissue- and time-specific manner and, more importantly, demonstrates DMF-dependent upregulation of ${ }^{A} \gamma$-globin and heme detoxification and vascular protective mechanisms in vivo.

Chronic dosing studies in Townes SCD mice were carried out to evaluate long-term ability of DMF to increase $\mathrm{HbF}$ expression in blood and improve disease parameters and anemia in SCD mice. Orally administered DMF at $100 \mathrm{mg} / \mathrm{kg}$, which has been shown previously to elevate Nrf2 targets in mice (32), resulted in a significant increase in $\mathrm{HbF}$ levels in rbc. A second chronic study with DMF at $50 \mathrm{mg} / \mathrm{kg}$ twice daily was carried out. This twice-a-day dosing regimen maintains MMF activity, since a single dose of DMF showed optimal Nrf2 target gene effects for less than 12 hours, as shown in our own study (Figure 5) and documented in previous studies (32). DMF-treated animals presented with a reduction in anemia, as demonstrated by an increase in several hematological parameters such as rbc counts, total $\mathrm{Hb}$, and MCHC, as well as a reduction in other parameters such as RDW, HDW, and MCV. RDW is a measure of anisocytosis in anemia, and significant lowering of RDW indicates normalization of rbc size distribution, which points toward an improvement in the disease state. Similarly, HDW, is directly proportional to the percentage of dense cells in SCD patients (33). Dense cells, also known as irreversible sickle cells, are rbc that participate in the formation of heterocellular aggregates that are responsible for precipitating vaso-occlusive crisis in sickle cell patients. HDW also correlates with RDW in the CBC. In patients with SCD, the fraction of dense rbc (or irreversibly sickled cells) is increased by HbS polymerization. Increasing $\mathrm{HbF}$ decreases the fraction of dense rbc (37). An increased HDW has been shown to correlate with an increase in dense rbc in human SCD patients (33). In DMF-treated mice, both HDW and RDW showed a significant reduction compared with vehicle-treated mice, which signifies both normalization of anemia and, indirectly, a reduction in dense cells.

In addition to the beneficial effects on $\gamma$-globin expression and hematological parameters, DMF also induced haptoglobin in the liver, which led to reduction in extracellular $\mathrm{Hb}$ in plasma. Haptoglobin is an Nrf2-dependent gene, whose key function is to sequester extracellular $\mathrm{Hb}$ that is free in plasma, thus preventing the harmful effects of hemolysis. Free $\mathrm{Hb}$ can be potentially converted to heme, which is involved in exacerbation of vascular inflammation in SCD. Sequestering $\mathrm{Hb}$ via haptoglobin is an important mechanism that plays a key role in reducing vascular inflammation in SCD. In addition to haptoglobin, other hepatic acute phase proteins were tested to assess if the response observed indicates potential activation of the acute phase response. However, RNA-seq study of liver clearly demonstrated that other acute phase response genes such as serum amyloid A, ceruloplasmin, and ALT were not regulated by DMF, indicating that the haptoglobin response is specific to the Nrf2 activation induced by DMF (Supplemental Figure 1). 
A

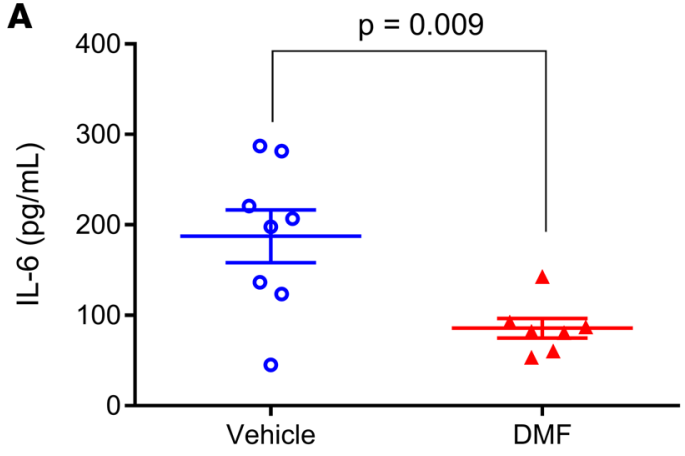

C

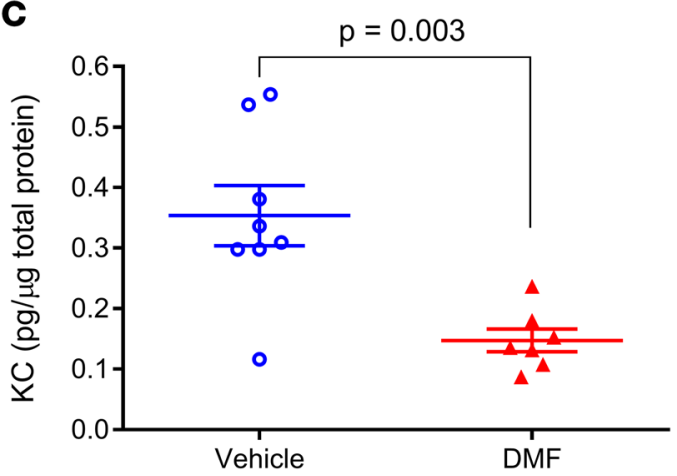

B

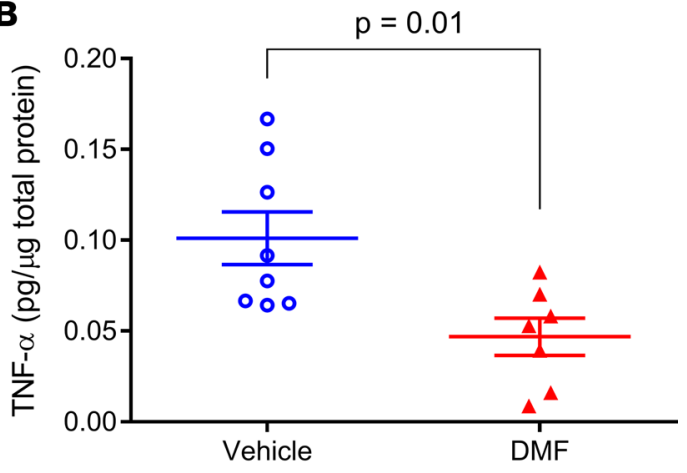

D

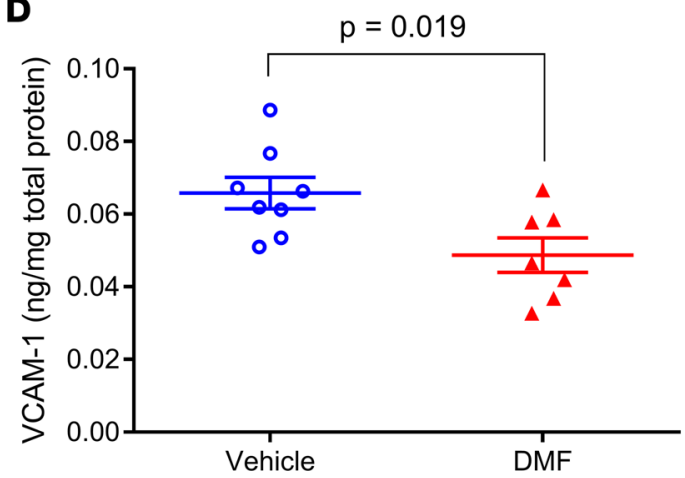

Figure 9. Chronic DMF treatment decreases inflammation and adhesion markers in SCD mice. Townes SCD SS mice administered $50 \mathrm{mg} / \mathrm{kg}$ DMF (IP, BID) or vehicle for 6 weeks were sacrificed, and liver homogenates and plasma samples were subjected to a multiplex cytokine assay. Cytokine levels were normalized to total protein levels in liver homogenates and expressed as pg/ $\mu \mathrm{g}$ total protein. (A) Plasma levels of IL-6, (B) hepatic levels of TNF- $\alpha$, and (C) hepatic levels of keratinocyte chemoattractant (KC, a murine ortholog of IL-8) were determined. (D) Hepatic levels of VCAM-1 were quantified by an ELISA, normalized to total protein in the homogenates, and expressed as $\mathrm{ng} / \mathrm{mg}$ protein. Results are expressed as mean $\pm \mathrm{SEM}$ and $n=7-8$ for all the panels. All $P$ values calculated with student $t$ test, 2 -tailed.

DMF-treated mice showed a reduction in several key cytokines that are elevated in SCD patients, such as IL-6 and TNF- $\alpha$, as well as the vascular adhesion integrin, VCAM-1. VCAM-1 is an important marker of vascular inflammation in SCD and serves as a ligand for VLA-4, a major adhesion molecule present on the surface of reticulocytes and leukocytes that is responsible for adhesive interactions between cells and with the endothelium (38). DMF-treated mice showed about a $60 \%$ reduction in plasma IL-6 levels and a more than $50 \%$ reduction in liver TNF- $\alpha$ and VCAM-1 levels. In summary, results from chronic DMF treatment illustrate that $\mathrm{DMF}$ induces $\mathrm{HbF}$, improves $\mathrm{Hb}$ level, and modulates the proinflammatory state in SCD. This beneficial reduction in proinflammatory cytokines and markers of inflammation in SCD mice is in agreement with previously published studies in an SCD mouse model where Nrf2 is genetically activated by decreasing expression of Keap1 (28) or chronic treatment with DMF (34).

Our present study is consistent with previous work showing that Nrf2 is a positive regulator of $\gamma$-globin expression $(25,29)$ and with the observation that both ARE sequences in the HBG1 and HBG2 gene promoters are completely conserved (24). This suggests a biological role for Nrf2 activation of ${ }^{A} \gamma$-globin and ${ }^{G} \gamma$-globin expression during erythropoiesis. A likely site for the role of Nrf2 may be in the embryonic fetal liver, where the crucial regulator of $\mathrm{Hb}$ expression, GATA2/GATA-1, first switches on fetal liver hematopoietic stem cell activity (39). Among the many genes affected by GATA-1 are genes in the pathway for heme biosynthesis, including 5-aminolevulinate synthase and porphobilinogen deaminase (40). There is a critical need to maintain a balance between the rates of heme biosynthesis and the expression of globin genes in order to limit production of unwanted ROS by excess free heme. Regulation of this balance of heme and globin is triggered when free heme levels are too low to bind the heme-binding domains of heme-regulated eIF2 $\alpha$ kinase (HRI), an intracellular heme sensor. By phosphorylating the $\alpha$-subunit of eIF2 and impairing translation, HRI is able to inhibit protein synthesis of globins during heme deficiency (41). 
A

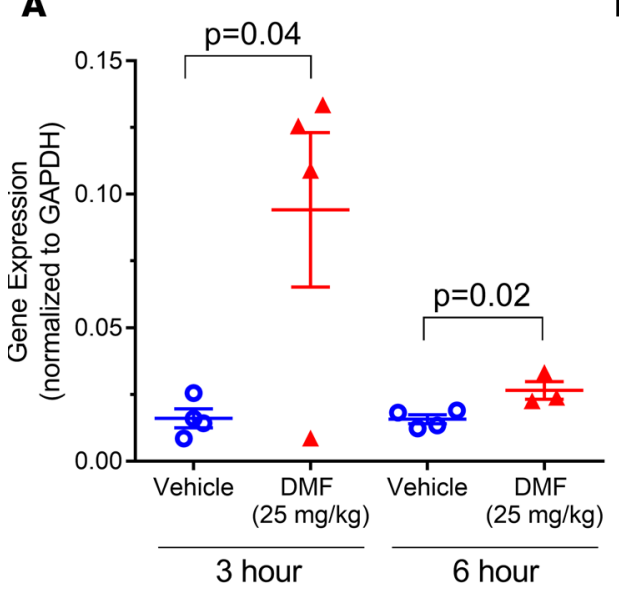

B

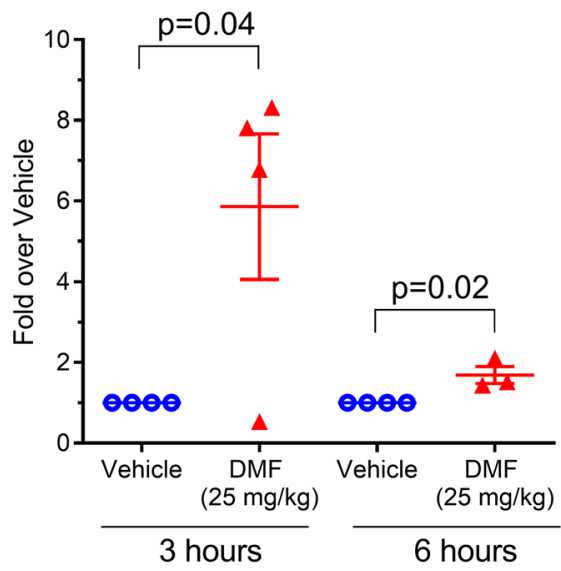

C

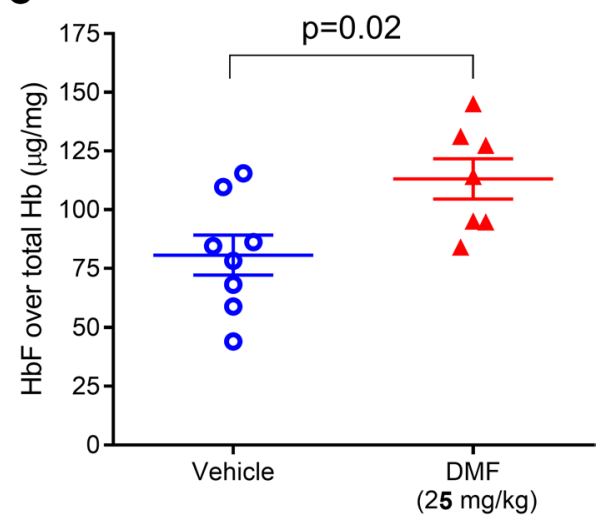

Figure 10. Chronic DMF treatment increases HbF mRNA and protein in nonhuman primates. BM mRNA from nonanemic cynomolgus monkeys treated chronically with daily oral doses of either $25 \mathrm{mg} / \mathrm{kg}$ DMF or vehicle was subjected to real-time PCR to measure $\gamma$-globin gene expression levels, which were normalized to GAPDH. Samples tested were obtained from 2 sets of animals at either 3 hours or 6 hours following the last dose of DMF. (A) $\gamma$ - $G$ lobin mRNA expression levels normalized to GAPDH $(n=3-4)$, (B) fold change in $\gamma$-globin mRNA induction for DMF-treated group over vehicle group at 2 time points $(n=3-4)$, and (C) HbF protein levels in rbc measured by ELISA and normalized to total hemoglobin ( $n=7-8)$. Results are reported as mean \pm SEM; $P<0.05$, calculated using student's $t$ test, 2-tailed.

As an additional control element, we suggest that increased levels of heme production trigger the expression of higher levels of $\gamma$-globins by a mechanism utilizing Nrf2 and the well-characterized Maf family of transcription factors $(42,43)$. Increasing levels of free heme bind Bach-1 to disrupt the Bach-Maf heterodimeric repressor complex, allowing release of the Maf component. The free Maf, in turn, forms an active Nrf2-Maf transcription complex to initiate expression of HO-1 $(44,45)$ and other genes, including $\gamma$-globin. In this model, the GATA-1-triggered increase in heme synthesis in fetal liver will be directly modulated by an Nrf2-driven increase in the expression of $\mathrm{HbF}$. Further studies are needed to confirm this mechanism.

Using SCD donor erythroid progenitor cells, an SCD mouse model, and nonanemic primates, we demonstrate that DMF can induce expression of $\gamma$-globin and other Nrf2-dependent genes. Chronic DMF dosing increases $\mathrm{HbF}$, with significant reduction in hemolysis. Activation of the Nrf2 pathway in SCD, thus, has multiple beneficial effects, as illustrated in Figure 11. Elevated HbF levels from BM, as well as a fortified heme detoxification response, can work in concert to alleviate many of the symptoms of the disease, such as reduction in sickling and decrease in hemolysis. Antiinflammatory actions, reduction in sickling, and removal of heme byproducts can, thus, alleviate vascular inflammation, which is one of the underlying pathological manifestations in SCD, thereby reducing the incidence of vaso-occlusions. Together, these findings suggest that the actions of DMF may have potential to ameliorate the disease state in SCD patients.

\section{Methods}

Reagents and antibodies. StemSpan SfemII (catalog 09655) and Erythroid Supplement (catalog 02692) were purchased from Stem Cell Technologies. DMF (catalog 242926) was obtained from MilliporeSigma, Dottikon Exclusive Synthesis AG, (catalog 27081.0201), or Biogen. MMF (catalog 651419) and HU (catalog H8627) were purchased from MilliporeSigma. FITC-labeled HbF antibody (catalog MHFH014), Triton X-100 (catalog HFH10) and Hoechst 33342 (catalog R37605) were purchased from Invitrogen. Other antibodies used for cell surface-marker staining and flow cytometry analysis, including anti-CD235a-PE (cata$\log$ 12-9987-82) and anti-CD71-APC (catalog 17-0719-42) were purchased from eBioscience.

ChIP assay. Human KU812 erythroleukemia cells were cultured using previously published procedures (36). ChIP assays were performed with a commercial kit (EZ-ChIP, MilliporeSigma) using a previously described protocol (46) with the following modifications. KU812 cells (ATCC) were cross-linked with 1\% formaldehyde for 15 minutes and then nuclei isolated using cell lysis buffer containing protease inhibitors (1 $\mu \mathrm{g} / \mathrm{ml}$ leupeptin, $1 \mathrm{mM}$ phenymethylsulphonyl fluoride, $1 \mu \mathrm{g} / \mathrm{ml}$ aprotinin). DNA was isolated using nuclear lysis buffer and sonicated on ice for 9 pulses for 5 seconds each using a Sonicator 4000 machine (Misonix) to generate 400-500 bp fragments. Sonicated DNA was collected as the input and used to generate standard curves for qPCR analysis. Immunoprecipitations were performed with the remaining chromatin using an 

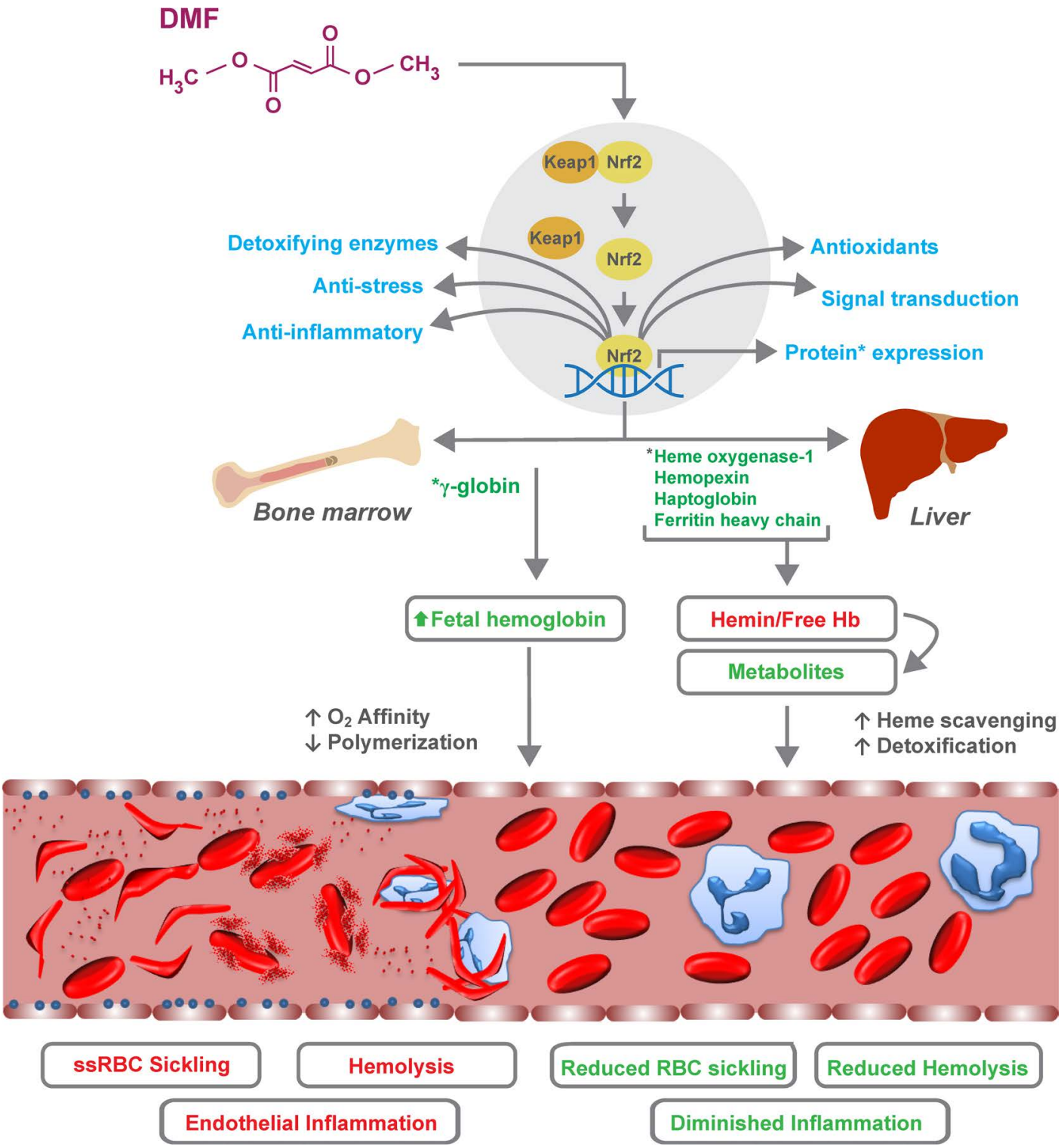

Figure 11. The Nrf2 activation pathway and sickle cell disease. Nrf2 activation by DMF has multiple potential beneficial effects in the setting of sickle cell disease, including induction of $\mathrm{HbF}$ by activation of the ARE site in the promoters for both the ${ }^{A} \gamma$-globin and ${ }^{\mathrm{C}} \gamma$-globin genes. In addition, increasing heme detoxification pathways in tissues and decreasing vascular inflammation will mitigate sickle cell disease vasculopathies.

antibody against TFIID or Nrf2 (catalog sc-13032x, Santa Cruz Biotechnology Inc.) and IgG served as the internal control. After DNA precipitation, chromatin was analyzed by qPCR using specific primers for the $\gamma$-globin promoter ARE, a negative control region $-1,222 \mathrm{bp}$ from G-CRE, and HS2 and HS3, of the LCR. Enrichment of DNA in IgG-precipitated samples were used as the internal control, and qPCR data were analyzed by the $2^{-\Delta \Delta \mathrm{Ct}}$ method.

Differentiation of erythroid progenitors from SCD PBMC. PBMC isolated from the whole blood of adult and pediatric SCD donors (Supplemental Methods 1 and Supplemental Table 1) were cultured and differentiated prior to exposure to test compounds using a 2-phase culture system (47). Compound incubations were performed either beginning from day 1 of culture or from day 8 of the culture, and cells were harvested for $\mathrm{HbF}$ induction by droplet digital PCR (ddPCR), flow cytometry, and HPLC analysis.

Quantitation of F-cells by flow cytometry. Flow cytometry was used to quantify the percentage of F-cells present in erythroid progenitors generated from human $\mathrm{CD} 34^{+}$cells or SCD donor PBMC as previously published (29) or using a protocol from Invitrogen. $\mathrm{HbF}$ levels in permeabilized cells were detected using FITC-conjugated anti-HbF antibody (catalog MHFH014, Invitrogen). Cells were also costained with 
anti-CD235-PE (catalog 12-9987-82, eBioscience), anti-CD71-APC (catalog 17-0719-42, eBioscience), and Hoechst 33342, in some instances, to identify different populations.

$\mathrm{HbF}$ subunit analysis by reversed phase ultra-performance liquid chromatography (UPLC). HbF subunit analysis by reversed-phase UPLC was performed essentially as described in ref. 48 using an ACQUITY UPLC system (Waters). Briefly, $5 \mu 1$ of lysate from CD $34^{+}$differentiated erythroid cells was injected into the UPLC system. A flow rate of $0.2 \mathrm{ml} /$ minute using a linear gradient of $38 \%-42.5 \%$ acetonitrile in water (Thermo Fisher Scientific) was used for elution. Peak areas corresponding to globin chains were quantitated using Agilent OpenLAB software.

Sickling assay. Differentiated erythoid cells were derived from erythroid progenitors generated from the PBMC fraction of SCD donor blood for 17-21 days in the presence of DMF or vehicle control (DMSO). Sterile PBS was deoxygenated by saturating with nitrogen gas. Differentiated cells were challenged under hypoxic conditions in deoxygenated PBS by suspending $5 \times 10^{6}$ cells in $400 \mu$ of buffer and incubating under $1 \%$ oxygen for 2 hours in a 24 -well-plate format. After incubation, cells were fixed with $20 \%$ formalin for 30 minutes at room temperature. Control sickle red cells were maintained under oxygenated conditions and were treated similarly. Postfixation cells were washed and analyzed for shape change using the Amnis ImageStream X Mark II Imaging Flow Cytometer (MilliporeSigma). Shape change was quantitated using IDEAS application software (MilliporeSigma) using a modified protocol (SIFCA) provided by Gregory J. Kato (Vascular Medical Institute, University of Pittsburgh, Pittsburgh, Pennsylvania, USA) (49, 50).

In vivo studies using Townes SCD mice. All animal experiments conformed to the guidelines of the appropriate IACUC and utilized Townes SCD mice (The Jackson Laboratory) (27). Three in vivo studies were carried out.

In the acute single-dose study, Townes mice, 8-10 weeks old, were administered a single oral dose of $100 \mathrm{mg} / \mathrm{kg}$ DMF in $0.8 \%$ HPMC. At 3, 6, and 24 hours after dosing, groups of mice were euthanized, and liver, spleen, whole blood, and BM were collected for mRNA analysis as described below.

In the chronic oral gavage study, Townes mice, $8-10$ weeks old, were dosed with $100 \mathrm{mg} / \mathrm{kg}$ DMF or vehicle by PO once daily for 6 days a week for a duration of 7 weeks. Whole blood was collected during weeks 4 and 7 for $\mathrm{HbF}$ protein analysis using Western blotting.

In the chronic i.p. study, 8- to 10 -week-old Townes mice were dosed with $50 \mathrm{mg} / \mathrm{kg}$ of DMF in $0.08 \%$ HPMC twice a day for 6 weeks. After euthanasia, whole blood samples were collected for performing CBC using an Advia 120 Hematology System (Siemens Healthcare). Plasma was collected from blood samples and snap frozen for cytokine and plasma-free $\mathrm{Hb}$ analysis. Liver and spleen samples were harvested, snap frozen, and stored for cytokine and protein analyses. Plasma samples and liver homogenates were assayed for cytokines using a multiplex proinflammatory murine cytokine assay kit (Meso Scale Devices).

$R N A$ isolation and quantitation of gene expression. RNA was extracted from cell pellets using the RNeasy kit (Qiagen) following manufacturer's protocol. For mouse tissues such as spleen, BM, and liver, samples were first homogenized in RLT buffer using Tissuelyser LT, and RNA was extracted using the RNeasy Plus kit (all from Qiagen). Whole blood total mRNA was isolated using the QIAamp RNA blood mini kit (Qiagen). Reverse transcriptase reaction was performed using Vilo Mastermix (Life Technologies, Thermo Fisher Scientific) to obtain cDNA. Transcripts were quantitated using either droplet ddPCR (Bio-Rad) or Taqman-based real-time PCR using protocol and guidelines from the manufacturer. RNA-seq was performed for liver and spleen samples. A library construction was completed using TruSeq Stranded mRNA sample preparation kit (Illumina Inc.) according to manufacturer's recommendations. Pooled libraries were clustered using HiSeq PE Cluster kit and sequenced on a HiSeq 2500 Sequencing system (Illumina Inc.) using 50/50 paired-end sequencing in high-output mode. The STAR RNA-Seq aligner was used to map the paired-end RNA sequences to the mouse genome (51). Gene and transcript abundances were determined using the Expectation Maximization (RSEM) algorithm (52). Differentially expressed genes were identified using the DESEQ2 algorithm (53). The RNA-seq results were deposited into the National Center for Biotechnology Information (NCBI) Gene Expression Omnibus (GEO) with the accession number GSE105035.

Protein isolation, Western blotting analysis, and HbF ELISA. Frozen liver and spleen tissue samples were used for protein isolation using the Tissue Lyser LT system (Qiagen) based on manufacturer's instructions. Whole blood was lysed with hemolysate reagent (Helena Laboratories). Protein concentration in tissue and whole blood lysates were determined using BCA assay. Standard Western blotting analysis methods were used to detect whole blood and splenic $\gamma$-globin (rabbit anti-human $\mathrm{Hb}^{\mathrm{G}} \gamma$; catalog PA5-29006; Thermo Fisher Scientific) and hepatic haptoglobin (using sheep anti-mouse haptoglobin; catalog AF4409; R\&D Systems). Spleen homogenates from the chronic IP study were also used for measuring $\mathrm{HbF}$ levels using an ELISA kit (Bethyl Laboratories). 
Assays for cell-free Hb, cytokines, and VCAM-1. Plasma cell-free $\mathrm{Hb}$ was quantified in isolated plasma using a colorimetric $\mathrm{Hb}$ assay kit (catalog MAK115-1KT, MilliporeSigma). Plasma samples and liver protein homogenates from the chronic IP study were used for measuring levels of cytokines using mouse proinflammatory 10-plex multiplex ELISA kit (Meso Scale Diagnostics). The plates were read and analyzed on a Meso Scale Sector 600 instrument (Meso Scale Diagnostics). For liver samples, the data obtained were normalized to total protein in the sample as measured by the BCA protein assay. Liver protein homogenates were also tested for VCAM-1 using ELISA (R\&D Systems).

In vivo studies in nonhuman primates. Experiments with cynomolgus monkeys were performed at Charles River Laboratories and conformed to the guidelines of the Institutional Animal Care and Use Committee (IACUC). Cynomolgus monkeys, aged 2.6-4.2 years, were orally (nasogastric) dosed with $25 \mathrm{mg} / \mathrm{kg} \mathrm{DMF}$ for $92-93$ consecutive days. The dose of $25 \mathrm{mg} / \mathrm{kg}$ was derived from a previous toxicology study performed by Biogen. Animals were euthanized in 2 cohorts - one at 3 hours and another at 6 hours after the last dose of DMF. BM samples were collected from animals after euthanasia, and mRNA was isolated. Real-time PCR was used to determine the expression levels of $\gamma$-globin normalized to GAPDH levels. Blood samples collected on day 91 were tested for $\mathrm{HbF}$ levels using a modified alphalisa-based $\mathrm{HbF}$ detection assay (Perkin Elmer) with a commercially available $\mathrm{HbF}$ antibody (Bethyl Laboratories) based on the manufacturer's instructions.

Statistics. Unpaired, 2-tailed $t$ tests were performed to determine statistically significant differences between groups using Prism 6.0c Software (GraphPad) or Excel (Microsoft), and $P$ values less than 0.05 were deemed significant. Experiments with multiple groups and vehicle controls were analyzed in addition with a one-way ANOVA test to determine if the $P$ values of the means were significantly different from each other. $P$ values from which estimates of FDRs were extracted were calculated using the BenjaminiHochberg algorithm (54). Also, a Bonferroni adjusted $P$ value was also ascertained in these results. Results for all the experiments are represented as mean \pm SEM.

Study approval. In vivo experiments with mice conformed to the guidelines of the IACUC of Biogen and Augusta University. Experiments with cynomolgus monkeys were performed at Charles River Laboratories following protocol guidelines from the institutional IACUC and subjected to United States Department of Agriculture approvals. Blood collection from sickle cell donors was performed upon informed consent protocols described under the IRB approval by Western Institutional Review Board (Puyallup, Washington, USA) and the IRB of the Sickle Cell Clinic at Augusta University (Augusta, Georgia, USA).

\section{Author contributions}

SK contributed experimental design and execution, data analysis, and manuscript preparation; BP contributed project conception and funding, pediatric and adult donor recruitment, experimental design, data analysis, clinical guidance, and manuscript preparation; DG contributed experimental design and execution, data analysis, and manuscript preparation; SS contributed experimental design and execution, data analysis, and manuscript preparation; BL contributed experimental design and execution of primary erythroid cultures and flow cytometry, data analysis, and manuscript preparation; LM contributed experimental design and execution of mouse studies, data analysis, and manuscript preparation; JB contributed experimental design and execution of mouse studies, data analysis, and manuscript preparation; NM contributed experimental design and execution, patient recruitment, and manuscript preparation; TT contributed experimental design and execution of monkey study; IS contributed experimental design and execution of monkey study; HL contributed experimental design and execution of mouse RNA-seq study; BFV contributed experimental design and execution, data analysis, and manuscript preparation; WEH contributed experimental design, patient recruitment, and manuscript preparation; and DRL contributed experimental design, adult patient recruitment, data analysis, and manuscript preparation.

\section{Acknowledgments}

The authors would like to thank Vu Hong for help with HPLC analysis of Hb samples. A portion of this research was supported by a grant from Biogen to BP.

Address correspondence to: David R. Light, 225 Second Avenue, Waltham, Massachusetts 02451, USA. Phone: 617.914.6910; Email: david.light@bioverativ.com. 
1. Kato GJ, Hebbel RP, Steinberg MH, Gladwin MT. Vasculopathy in sickle cell disease: Biology, pathophysiology, genetics, translational medicine, and new research directions. Am J Hematol. 2009;84(9):618-625.

2. Vercellotti GM, Belcher JD. Not simply misshapen red cells: multimolecular and cellular events in sickle vaso-occlusion. $J$ Clin Invest. 2014;124(4):1462-1465.

3. Belcher JD, Beckman JD, Balla G, Balla J, Vercellotti G. Heme degradation and vascular injury. Antioxid Redox Signal. 2010;12(2):233-248.

4. Ghosh S, et al. Extracellular hemin crisis triggers acute chest syndrome in sickle mice. J Clin Invest. 2013;123(11):4809-4820.

5. Belcher JD, et al. Heme triggers TLR4 signaling leading to endothelial cell activation and vaso-occlusion in murine sickle cell disease. Blood. 2014;123(3):377-390.

6. Schaer DJ, Buehler PW, Alayash AI, Belcher JD, Vercellotti GM. Hemolysis and free hemoglobin revisited: exploring hemoglobin and hemin scavengers as a novel class of therapeutic proteins. Blood. 2013;121(8):1276-1284.

7. Chintagari NR, Nguyen J, Belcher JD, Vercellotti GM, Alayash AI. Haptoglobin attenuates hemoglobin-induced heme oxygenase-1 in renal proximal tubule cells and kidneys of a mouse model of sickle cell disease. Blood Cells Mol Dis. 2015;54(3):302-306.

8. Hebbel RP, Boogaerts MA, Eaton JW, Steinberg MH. Erythrocyte adherence to endothelium in sickle-cell anemia. A possible determinant of disease severity. N Engl J Med. 1980;302(18):992-995.

9. Telen MJ. Beyond hydroxyurea: new and old drugs in the pipeline for sickle cell disease. Blood. 2016;127(7):810-819.

10. Charache S, et al. Effect of hydroxyurea on the frequency of painful crises in sickle cell anemia. Investigators of the Multicenter Study of Hydroxyurea in Sickle Cell Anemia. N Engl J Med. 1995;332(20):1317-1322.

11. Terasawa T, Ogawa M, Porter PN, Karam JD. G gamma and A gamma globin-chain biosynthesis by adult and umbilical cord blood erythropoietic bursts and reticulocytes. Blood. 1980;56(1):93-97.

12. Ogawa M, Porter PN. Fetal hemoglobin biosynthesis in clonal cell culture. Tex Rep Biol Med. 1980;40:55-65.

13. Superti-Furga G, Barberis A, Schaffner G, Busslinger M. The -117 mutation in Greek HPFH affects the binding of three nuclear factors to the CCAAT region of the gamma-globin gene. EMBO J. 1988;7(10):3099-3107.

14. Tasiopoulou M, Boussiou M, Sinopoulou K, Moraitis G, Loutradi-Anagnostou A, Karababa P. G gamma-196 C-->T, A gamma-201 C-->T: two novel mutations in the promoter region of the gamma-globin genes associated with nondeletional hereditary persistence of fetal hemoglobin in Greece. Blood Cells Mol Dis. 2008;40(3):320-322.

15. Toma S, Tenorio M, Oakley M, Thein SL, Clark BE. Two novel mutations (HBG1: c. -250C > T and HBG2: c. -250C > T) associated with hereditary persistence of fetal hemoglobin. Hemoglobin. 2014;38(1):67-69.

16. Steinberg MH, Chui DH, Dover GJ, Sebastiani P, Alsultan A. Fetal hemoglobin in sickle cell anemia: a glass half full? Blood. 2014;123(4):481-485

17. Dasgupta T, Fabry ME, Kaul DK. Antisickling property of fetal hemoglobin enhances nitric oxide bioavailability and ameliorates organ oxidative stress in transgenic-knockout sickle mice. Am J Physiol Regul Integr Comp Physiol. 2010;298(2):R394-R402.

18. Xu J, et al. Correction of sickle cell disease in adult mice by interference with fetal hemoglobin silencing. Science. 2011;334(6058):993-996.

19. Steinberg MH, et al. The risks and benefits of long-term use of hydroxyurea in sickle cell anemia: A 17.5 year follow-up. Am J Hematol. 2010;85(6):403-408.

20. Voskaridou E, et al. The effect of prolonged administration of hydroxyurea on morbidity and mortality in adult patients with sickle cell syndromes: results of a 17-year, single-center trial (LaSHS). Blood. 2010;115(12):2354-2363.

21. Cui S, et al. The LSD1 inhibitor RN-1 induces fetal hemoglobin synthesis and reduces disease pathology in sickle cell mice. Blood. 2015;126(3):386-396.

22. Moutouh-de Parseval LA, et al. Pomalidomide and lenalidomide regulate erythropoiesis and fetal hemoglobin production in human CD34+ cells. J Clin Invest. 2008;118(1):248-258.

23. Malhotra D, et al. Global mapping of binding sites for Nrf2 identifies novel targets in cell survival response through ChIP-Seq profiling and network analysis. Nucleic Acids Res. 2010;38(17):5718-5734.

24. de Vooght KM, van Wijk R, Ploos van Amstel HK, van Solinge WW. Characterization of the $-16 \mathrm{C}>\mathrm{G}$ sequence variation in the promoters of both HBG1 and HBG2: convergent evolution of the human gamma-globin genes. Blood Cells Mol Dis. 2007;39(1):70-74

25. Macari ER, Lowrey CH. Induction of human fetal hemoglobin via the NRF2 antioxidant response signaling pathway. Blood. 2011;117(22):5987-5997.

26. Viglietta V, et al. Efficacy of delayed-release dimethyl fumarate in relapsing-remitting multiple sclerosis: integrated analysis of the phase 3 trials. Ann Clin Transl Neurol. 2015;2(2):103-118.

27. Wu LC, Sun CW, Ryan TM, Pawlik KM, Ren J, Townes TM. Correction of sickle cell disease by homologous recombination in embryonic stem cells. Blood. 2006;108(4):1183-1188.

28. Keleku-Lukwete N, et al. Amelioration of inflammation and tissue damage in sickle cell model mice by Nrf2 activation. Proc Natl Acad Sci USA. 2015;112(39):12169-12174.

29. Promsote W, et al. Monomethylfumarate induces $\gamma$-globin expression and fetal hemoglobin production in cultured human retinal pigment epithelial (RPE) and erythroid cells, and in intact retina. Invest Ophthalmol Vis Sci. 2014;55(8):5382-5393.

30. Sheikh SI, et al. Tolerability and pharmacokinetics of delayed-release dimethyl fumarate administered with and without aspirin in healthy volunteers. Clin Ther. 2013;35(10):1582-1594.e9.

31. Dibbert S, Clement B, Skak-Nielsen T, Mrowietz U, Rostami-Yazdi M. Detection of fumarate-glutathione adducts in the portal vein blood of rats: evidence for rapid dimethylfumarate metabolism. Arch Dermatol Res. 2013;305(5):447-451.

32. Brennan MS, et al. Pharmacodynamics of Dimethyl Fumarate Are Tissue Specific and Involve NRF2-Dependent and -Independent Mechanisms. Antioxid Redox Signal. 2016;24(18):1058-1071.

33. Billett HH, Fabry ME, Nagel RL. Hemoglobin distribution width: a rapid assessment of dense red cells in the steady state and during painful crisis in sickle cell anemia. J Lab Clin Med. 1988;112(3):339-344.

34. Belcher JD, et al. Control of Oxidative Stress and Inflammation in Sickle Cell Disease with the Nrf2 Activator Dimethyl Fumarate. Antioxid Redox Signal. 2017;26(14):748-762.

35. Ngo DA, et al. Fetal haemoglobin levels and haematological characteristics of compound heterozygotes for haemoglobin S and 
deletional hereditary persistence of fetal haemoglobin. Br J Haematol. 2012;156(2):259-264.

36. Zein S, et al. Identification of fetal hemoglobin-inducing agents using the human leukemia KU812 cell line. Exp Biol Med (Maywood). 2010;235(11):1385-1394

37. Fabry ME, et al. Dense cells in sickle cell anemia: the effects of gene interaction. Blood. 1984;64(5):1042-1046.

38. White J, et al. VLA-4 blockade by natalizumab inhibits sickle reticulocyte and leucocyte adhesion during simulated blood flow. Br J Haematol. 2016;174(6):970-982.

39. Katsumura KR, Bresnick EH, GATA Factor Mechanisms Group. The GATA factor revolution in hematology. Blood. 2017;129(15):2092-2102.

40. Lake-Bullock H, Dailey HA. Biphasic ordered induction of heme synthesis in differentiating murine erythroleukemia cells: role of erythroid 5-aminolevulinate synthase. Mol Cell Biol. 1993;13(11):7122-7132.

41. Chen JJ. Translational control by heme-regulated eIF2 $\alpha$ kinase during erythropoiesis. Curr Opin Hematol. 2014;21(3):172-178.

42. Katsuoka F, Yamazaki H, Yamamoto M. Small Maf deficiency recapitulates the liver phenotypes of Nrf1-and Nrf2-deficient mice. Genes Cells. 2016;21(12):1309-1319.

43. Katsuoka F, Yamamoto M. Small Maf proteins (MafF, MafG, MafK): History, structure and function. Gene. 2016;586(2):197-205.

44. Sun J, Brand M, Zenke Y, Tashiro S, Groudine M, Igarashi K. Heme regulates the dynamic exchange of Bach1 and NF-E2-related factors in the Maf transcription factor network. Proc Natl Acad Sci USA. 2004;101(6):1461-1466.

45. Shan Y, Lambrecht RW, Ghaziani T, Donohue SE, Bonkovsky HL. Role of Bach-1 in regulation of heme oxygenase-1 in human liver cells: insights from studies with small interfering RNAS. J Biol Chem. 2004;279(50):51769-51774

46. Kalra IS, Alam MM, Choudhary PK, Pace BS. Krüppel-like Factor 4 activates HBG gene expression in primary erythroid cells. Br J Haematol. 2011;154(2):248-259.

47. Hebiguchi M, et al. Dynamics of human erythroblast enucleation. Int J Hematol. 2008;88(5):498-507.

48. Chang KH, et al. Long-Term Engraftment and Fetal Globin Induction upon BCL11A Gene Editing in Bone-Marrow-Derived CD34(+) Hematopoietic Stem and Progenitor Cells. Mol Ther Methods Clin Dev. 2017;4:137-148.

49. van Beers EJ, et al. Imaging flow cytometry for automated detection of hypoxia-induced erythrocyte shape change in sickle cell disease. Am J Hematol. 2014;89(6):598-603

50. Fertrin KY, Samsel L, van Beers EJ, Mendelsohn L, Kato GJ, McCoy JP. Sickle Cell Imaging Flow Cytometry Assay (SIFCA) Methods Mol Biol. 2016;1389:279-292.

51. Dobin A, et al. STAR: ultrafast universal RNA-seq aligner. Bioinformatics. 2013;29(1):15-21.

52. Li B, Dewey CN. RSEM: accurate transcript quantification from RNA-Seq data with or without a reference genome. BMC Bioinformatics. 2011;12:323

53. Love MI, Huber W, Anders S. Moderated estimation of fold change and dispersion for RNA-seq data with DESeq2. Genome Biol. 2014;15(12):550.

54. Benjamini Y, Hochberg Y. Controlling the false discovery rate: a practical and powerful approach to multiple testing. $J R$ Stat Soc Series B Stat Methodol. 1995;57(1):289-300. 